\title{
La articulación de un nivel local supramunicipal y la Administración periférica de las Comunidades Autónomas. El conflicto provincias-comarcas y el caso de las Comunidades Autónomas uniprovinciales ${ }^{1}$
}

\author{
Fernando García Rubio \\ Profesor titular de derecho administrativo. URJC \\ Técnico de administración general del Ayuntamiento de Madrid \\ fernando.rubio@urjc.es
}

\section{INTRODUCCIÓN. SISTEMA LOCAL Y ORGANIZACIÓN AUTONÓMICA}

\section{I.1. Planteamiento}

Una de las grandes críticas que por numerosas fuentes se vierten sobre el sistema constitucional de las Entidades locales de segundo grado (en especial las diputaciones provinciales) es su innecesariedad por la yuxtaposición con las estructuras de las CC.AA.

Así nuestro complejo y delicado sistema de organización territorial derivado del consenso alcanzado por los constituyentes para el título VIII de la Carta Magna articula tanto unas corporaciones locales de segundo grado de planta estatal en su artículo 141, como en un principio una posible articulación por parte de las diferentes CC.AA de circunscripciones, e incluso entidades con personalidad jurídica en su estructuración territorial, tal y como prevé el art. 152.3 de la Ley de leyes. El trabajo del profesor Delgado Piqueras en este volumen así lo atestigua.

Así debe reseñarse que la Sentencia 168/2016, de 6 de octubre del Tribunal Constitucional, sobre el recurso del Principado de Asturias sobre varios aspectos de la LRSAL viene a cerrar el sistema, por el momento.

Esta circunstancia de existencia de entidades locales de segundo grado con una regulación, al menos básica, estatal, con otras de nueva planta y configuración autonómica ha dado lugar a una desincronía que supuso ya una primera jurisprudencia del Tribunal Constitucional en defensa de la estructura de las Diputaciones, con su «garantía institucional» y la clara competencia estatal para su regulación y contenido.

Por otra parte las diferentes CC.AA han ido implantando sus propias organizaciones territoriales e incluso Aragón, Cataluña, Castilla y León (solo para el Bierzo) y el País Vasco (solo para el territorio histórico de Álava) han implantado sistemas de entidades locales de segundo grado no provinciales, eso si compatibilizándolo con las Diputaciones, de forma voluntaria en unos supuestos y forzado por el TC en otros.

De hecho el único intento formal de suprimirlas es el renuente de Cataluña desde el comienzo de la autonomía, puesto que el resto de CC.AA, pluriprovinciales claro, han asumido la institución y la han incorporado a sus legislaciones.

Obviamente como parte esencial de su autonomía las CC.AA se han dotado de su propia organización territorial, adaptándose en unos casos a la estructura previa de las provincias u obviando esta, total o parcialmente en otras, como manifestación inherente a su potestad de organización.

1 Fernando García Rubio es Profesor titular de derecho administrativo de la Universidad Rey Juan Carlos (URJC) y Técnico de administración general del Ayuntamiento de Madrid. 
Ya desde un comienzo ARGULLOL² señaló que por lo que se refiere a la potestad organizatoria de las propias Comunidades en sus primeras manifestaciones de las determinaciones estatutarias referidas a la articulación territorial de cada Comunidad Autónomas eran considerables las diferencias existentes entre los diversos Estatutos. En algunos casos se puso énfasis en la creación de nuevas entidades locales. En otros no existía la preocupación para establecer nuevos niveles necesarios de gobierno. En ocasiones primó un elemento de herencia histórica. De hecho el propio Argullol destacaba que en algunos casos la provincia estaba llamada a jugar un papel, en principio, fundamental como consecuencia de la propia extensión territorial de la Comunidad o incluso de su falta de vertebración. Al margen quedaban, como es lógico, las Comunidades Autónomas de carácter uniprovincial, en las que la provincia se subsumió de hecho en la Comunidad Autónoma y el órgano de gobierno tradicional de la provincia, la Diputación Provincial, desapareció en beneficio de los órganos propios de la Comunidad Autónoma.

Estas posibilidades estatutarias han servido a nuestro juicio en un primer momento como gran motor del desarrollo comarcal desde un punto de vista de organización jurídico-administrativo, por oposición a la figura de la Diputación provincial.

Así señalaremos que Cataluña siempre ha actuado de precursor en este aspecto, ya desde los Decretos de la Generalitat republicana de $1936^{3}$ ( 27 de Agosto y 23 de Diciembre), la ley de Alta montaña de 16 de marzo de $1983^{4}$ y siendo la primera Comunidad autónoma que gozó de una completa estructura comarcal sobre la integridad de su territorio.

La Constitución establece un ámbito competencial para las Comunidades Autónomas en relación con el régimen local ${ }^{5}$ que suponen unas limitaciones ${ }^{6}$ para el conjunto de las posibilidades reformadoras del legislador estatal en las materias de competencia autonómica, al menos en el sistema actual establecido por la interpretación del Tribunal Constitucional ${ }^{7}$ de dichos títulos competenciales y en buena medida para el régimen jurídico del ejercicio de la actividad y organización de las AA.PP.

El art. 141 de la CE, recoge institucionalmente la figura de la Provincia como entidad local estableciéndose esta entidad en un territorio, el provincial que tiene una doble configuración por un lado circunscripción para el cumplimiento de los fines del Estado y en su caso de las Comunidades Autónomas y por otra parte la determinación ya consabida de entidad local. Ese carácter de entidad local de la provincia de origen decimonónico en España como ya estudiaran Tomas Ramón FERNÁNDEZ ${ }^{8}$ y Jesús GONZÁLEZ SALINAS ${ }^{9}$ hace que el ente provincial tenga a su vez una doble vertiente, conforme a la configuración de la legislación sobre régimen local de carácter bifronte entre el Estado con sus bases y la legislación de las Comunidades Autónomas sobre el indicado espacio local en base a los títulos competenciales correspondientes de los diversos estatutos de autonomía.

2 ARGULLOL I MURGADAS, Enric, “La administración de las CC.AA”, Revista española de derecho constitucional, págs. 97-98.

3 Al respecto de dichos decretos NIETO GARCÍA, Alejandro, “Legislación del Parlamento de Cataluña sobre Comarcas”, págs. 119 a 130 de La Comarca como Ente Territorial. Generalitat de Catalunya 1984.

4 Un análisis de dicha ley lo tenemos en el artículo de LLISET BORRELL, Francisco, en el número 100-101 de la Revista de Administración Pública (1983).

5 Que ha sido específicamente ampliado por las reformas de los Estatutos de Autonomía de Cataluña, Andalucía, Comunidad Valenciana y Aragón, aprobados por Ley Orgánica 6/2006, de 19 de julio, de reforma del Estatuto de Autonomía de Cataluña, Ley Orgánica 2/2007, de 19 de marzo, de reforma del Estatuto de Autonomía para Andalucía, Ley Orgánica 1/2006, de 10 de abril, de Reforma de la Ley Orgánica 5/1982, de 1 de julio, de Estatuto de Autonomía de la Comunidad Valenciana, Ley Orgánica 5/2007, de 20 de abril, de reforma del Estatuto de Autonomía de Aragón y en menor medida Castilla y León, aprobado por Ley Orgánica 14/2007, de 30 de noviembre, de reforma del Estatuto de Autonomía de Castilla y León y Extremadura, aprobado por Ley Orgánica 1/2011, de 28 de enero, de reforma del Estatuto de Autonomía de la Comunidad Autónoma de Extremadura,

6 Este fenómeno que ha sido denominado “interiorización” del derecho local y en general puede consultarse a COSCULLUELA MONTANER, Luis y CARBONELL PORRAS, Eloísa (directores), Reforma Estatutaria y régimen local, Civitas-Thomson Reuters, Ministerio de Ciencia e Innovación, 2011, debemos destacar que al amparo de los títulos competenciales recogidos en su estatuto de autonomía, diversas Comunidades Autónomas han aprobado legislaciones en relación a esta materia, que pretenden incidir en la línea de la "interiorización" del derecho local en las CC.AA, y que han supuesto incluso antes de las reformas estatutarias del periodo 2006-2008, una impugnación de las capacidades legislativas del Estado sobre esa materia ante el Tribunal Constitucional, en los recursos 1523-2004 interpuesto por el Parlamento de Cataluña, 1598/2004 interpuesto por el Gobierno Catalán y 1741/2004 promovido por el Gobierno de Aragón, que han sido resueltos por la STC 103/2013, de 25 de abril . Sobre esta materia véase con respecto a la interiorización ORTEGA ÁLVAREZ, Luis, "El régimen local en los nuevos estatutos de autonomía", págs. 253 a 285 de Tratado de Derecho Municipal, obra colectiva dirigida por MUÑOZ MACHADO, Santiago. Iustel 2011, y con respecto a los límites de la facultad legislativa en la organización de los servicios públicos locales del Estado, a MONTOYA MARTíN, Encarnación, “Las formas de gestión de los servicios públicos locales: los entes instrumentales", dentro del Congreso Europeo sobre descentralización territorial y administración local. Sevilla, 9, 10 y 11 de mayo de 2007. Instituto Andaluz de Administración Pública, 2009, págs. 215 a 258.

7 Sobre el papel del alto interprete de la Carta Magna es imprescindible la obra de FERNÁNDEZ FARRERES, Germán, La contribución del tribunal constitucional al estado autonómico, lustel, 2005.

8 Tomás Ramón FERNÁNDEZ, “El gobierno interior de las provincias y de los pueblos en la Constitución de $1812 ”$, págs. 115 a 127 de la obra colectiva coordinada por Alberto RUIZ OJEDA, El gobierno local. Estudios en homenaje al profesor Luis Morell Ocaña. Iustel-Cosital, 2010.

9 Jesús GONZÁLEZ SALINAS, “La organización local en el siglo XIX, su regulación según el modelo de la Constitución de Cádiz", págs. 544 a 576 de la obra colectiva coordinada por José María BAÑO LEÓN y Juan CLIMENT BARBERÁ, Nuevas perspectivas del Régimen Local, Estudios en homenaje al profesor José M. ${ }^{a}$ Boquera Oliver, Tirant lo Blanch, Valencia, 2002. 
De hecho hay quien mantiene como el propio GARCÍA DE ENTERRÍA ${ }^{10}$ que se hace necesario superar la idea tradicional de la Provincia . Igualmente MORELL OCAÑA ${ }^{11}$ señala que la naturaleza compuesta por una unión de municipios de la Provincia, supone que el vinculo de integración de estos en la Provincia es mas profundo y genera unas consecuencias muy superiores a una mera unión, puesto que no es de esa naturaleza, la naturaleza de la Provincia, pero si matiza su función como entidad local. En ese sentido no debemos olvidar que la Provincia es en si misma una parte integrante de la organización territorial del estado, al mismo nivel en cuanto a su indisponibilidad que los municipios y que las propias Comunidades Autónomas, tal y como se deriva de la determinación literal del art. 137 de la Constitución. Pese a estas determinaciones y la persistencia de la Provincia y las propias Comunidades Autónomas, lo cierto es, tal y como afirma LEGUINA VILLA ${ }^{12}$, que es muy real la tentación que podían caer, de hecho han caído sostenemos nosotros, como forma de autoafirmarse las Comunidades Autónomas de la fuerza su propia cohesión interna, a costa del autogobierno de las entidades Intrarregionales.

\section{I.2. Modelos de organización provincial local}

En base a dicha circunstancia debemos destacar la articulación por parte de ORTEGA ÁLVAREZ y PORTA SEGUIDO ${ }^{13}$ de clasificar las provincias en relación con las Comunidades Autónomas en tres grandes modelos:

a) Por un lado el modelo de provincia por integración en las Comunidades Autónomas uniprovinciales no insulares, Por otro el de una organización provincial fuerte previsto en la ley del proceso autonómico y en tercer lugar de una organización provincial débil con unos mínimos competenciales, como consecuencia de la potenciación máxima del nivel autonómico y la creación de otro nivel territorial distinto de la provincia y de los municipios y que es competitivo con esta como son las Comarcas. Esa clasificación aunque sustancialmente valida olvida el caso catalán, con la recurrente pretensión de eliminar a la provincia como entidad local en el territorio de la comunidad autónoma de Cataluña.

b) Otra clasificación de los modelos provinciales en relación con los estatutos de las Comunidades Autónomas la realiza COSCULLUELA MONTANER ${ }^{14}$, en el cual diferencia entre el modelo vasco, el modelo catalán, el de las Comunidades Autónomas uniprovinciales y el de las Comunidades Autónomas pluriprovinciales. Clasificación con la que estamos mas en línea, toda vez que en la citada determinación clasificatoria se incorpora junto a otros el modelo foral, expresamente propiciado por la Disposición Adicional Primera de la Constitución, el estatuto de autonomía de Guernica y la Ley vasca de territorios históricos de 1984, que tiene como características la elección directa por los ciudadanos de los miembros de las juntas generales de cada uno de los territorios históricos y especialmente el «blindaje» de las normas forales (lo que serian ordenanzas para el resto de las Provincias) de los citados territorios históricos ante la jurisdicción contenciosa administrativa, siendo únicamente susceptibles de recurso de inconstitucionalidad ante el Tribunal Constitucional, conforme lo previsto por la Ley Orgánica 1/2010, de 19 de febrero en su Disposición Adicional Quinta, así como la modificación del art. 9.4. de la Ley Orgánica del Poder Judicial 6/1985. Refrendado con los nuevos preceptos del art. 25.6 y 32 bis LRBRL en esa línea ${ }^{15}$.

Por otro lado el modelo catalán ya en la determinación del Estatuto original de 1979 que recogía la integración de la comunidad Autónoma por las comarcas ubicadas en las «actuales provincias Barcelona, Tarragona, Lérida y Gerona» por lo que desde Cataluña nunca se vio especialmente con buenos ojos la figura de la Provincia como circunscripción provinente del Estado, aunque recuérdese, tal y como demostró MARTíN MATEO ${ }^{16}$, no hubo especial oposición a dicha división desde el territorio catalán en el momento de su implantación, como por otra parte en cuanto a la organización local propia de estas derivada de un régimen básico estatal.

10 Eduardo GARCíA DE ENTERRÍA, “Problemas actuales del Régimen local”, 3. edición, Thomson-Civitas, 2007 . La Provincia en el régimen local español, pág. 44 .

11 Luis MORELL OCAÑA, "La provincia”, dentro de la obra colectiva Tratado de derecho municipal, dirigida por Santiago MUÑOZ MACHADO. lustel, $3 .^{\text {a }}$ ed., 2010, tomo II.

12 Jesús LEGUINA, “la autonomía de los municipios y provincias a la ley básica de régimen local”, Revista de estudios de la administración local y autonómica, núm. 227, 1985.

13 Luis ORTEGA ÁLVAREZ y Francisco PORTA SEGUIDO, comentario art. 31 de la LRBRL, págs. 793 a 806 , y en concreto 802 dentro de la obra colectiva Comentarios a la ley reguladora de bases de régimen local, tomo 1, arts. 1-45, dirigida por Manuel REBOLLO PUIG, Tirant Lo blanch, Valencia 2007.

14 Luis COSCULLUELA MONTANER, "Problemática de la Provincia como entidad local”, págs. 99 a 124, de la obra colectiva dirigida por el mismo y Luis MEDINA ALCOZ, Crisis económica y reforma del régimen local, Civitas-Thomson Reuters, 2012 , y en concreto págs. 105 a 107.

15 Así mediante enmienda conjunta del PP y el PNV en el congreso se introduce como consecuencia de la Propuesta de Resolución, núm. 2 aprobada en el Congreso de los Diputados con ocasión del debate de política general en torno al estado de la nación una nueva redacción de la disposición adicional segunda de la LRBRL, mediante el art 1. treinta y cuatro de la LRSAL, enmienda núm. 260, págs. 186-188, BOCG de 30 de octubre de 2013. La resolución se encuentra en BOCG de 4 de marzo de 2013 y manifestaba: «El Congreso de los Diputados insta al Gobierno a que el texto del proyecto de Ley de racionalización y sostenibilidad de la administración local refleje expresamente la singularidad foral del entramado institucional vasco.».

16 Ramón MARTÍN MATEO, “Entes locales complejos”, La comarca, pág. 153. Editorial Trivium, 1987. 
En ese sentido ya la Ley 6/1980, de 17 de diciembre de transferencia urgente y plena de diputaciones catalanas a la Generalidad de Cataluña, era bastante clarificadora de dicha postura, puesto que tal y como recuerda COSCULLUELA MONTANER ${ }^{17}$, era un obstáculo para la ordenación territorial catalana que el Parlamento Autonómico deberá establecer, y pese a dicho establecimiento, añadimos nosotros, y tras la reforma estatutaria sigue siendo un problema.

Esta circunstancia que la sentencia del Tribunal Constitucional 32/1981, de 28 de julio ${ }^{18}$ impidió, ha sido claramente una constante en las voluntades legisladoras del Parlamento de Cataluña hasta la incorporación por el Estatuto de autonomía de 2006 de la determinación de la veguería como entidad local supramunicipal propia de Cataluña con numero mínimo de 5 y máximo de 7, tal y como se encargó de determinar la Ley de veguerías, y que el Tribunal Constitucional nuevamente en su sentencia 31/2010 ha impedido, puesto que tendrían que convivir la diputación Provincial y la veguería como entidad propia de Cataluña, salvo que se altere el territorio de las pretendidas demarcaciones vegueriales, o el Estado modifique por ley orgánica dichas circunscripciones provinciales adaptándoles a su vez a las veguerías.

c) El tercer modelo es el de las Comunidades Autónomas uniprovinciales en las que la Provincia se suprime por el propio Estatuto de Autonomía y la corporación provincial es la Comunidad Autónoma, pero manteniendo las funciones y determinaciones en relación con los Municipios de las Diputaciones tal y como es establece art. 40 de la Ley $7 / 1985$, de 2 de abril.

Con un parecido carácter nos encontramos con las determinaciones vinculadas con la Comunidad Foral de Navarra en su singularidad propia del carácter foral, tal y como se recoge en la Sentencia del Tribunal Constitucional 140/1990, de 20 de septiembre, en relación con la Disposición Adicional Primera de la Constitución y en otro sentido la de las Islas Baleares en la que la condición de entidad local supramunicipal queda atribuida a los Consells Insulares, ya desde el régimen preautonómico con el primer Estatuto de autonomía y con el Estatuto de Autonomía reformado, que simplemente añade con un carácter un poco estrambótico del carácter de consejo insular a Formentera, Consejo Insular unimunicipal.

d) El cuarto y último modelo de integración de relaciones entre la Provincia y la Comunidad Autónoma es el modelo que podemos llamar general o mayoritario, en su origen, vinculado a las Comunidades Autónomas de carácter pluriprovincial exceptuando la del País Vasco (aunque en esta se respeta el territorio provincial y las funciones locales de la entidad foral) y el catalán que al menos teóricamente pretende eliminar la Provincia. Este modelo, que tal y como destaca COSCULLUELA MONTANER ${ }^{19}$, incorpora a la Comunidad Autónoma gallega con las posibilidades previstas desde un primer momento por la Ley Orgánica de Armonización del proceso autonómico derivada del trabajo de la comisión de expertos sobre las autonomías territoriales y posteriormente, añadimos nosotros, puesto que muchas veces es olvidada la vigencia de dicha ley que sin carácter orgánico ni armonizador pero con valor de ley y por lo tanto vinculante a todos los efectos, recoge el sistema de la Ley de proceso autonómico en sus arts. 9 y 15, para que la Provincia además de entidad local puede ser entidad gestora con carácter ordinario de los servicios autonómicos en el territorio provincial.

Un aspecto este claro precedente de la administración única y de la evitación de duplicidades que fue claramente obviado ya desde el comienzo de la articulación del estado autonómico por la potestad legislativa de las comunidades autónomas en relación con su propia organización administrativa y territorial, que en todo momento soslayaron la gestión por entidades no controladas integradas en la organización autonómica de servicios propios independientemente de los aspecto políticos que sobre esa circunstancia concurren ${ }^{20}$.

\section{I.3. La discusión de la Entidad desde las Constituyentes y sus pretensiones de «vaciamiento» o sustitución por las comarcas.}

Ya en el seno de las Cortes constituyentes, la acepción provincial fue discutida también en cuanto a su configuración, tanto como entidad necesaria de la administración periférica del Estado, tal y como señala Sebastián

17 Luis COSCULLUELA MONTANER, op. cit., problemática de la provincia..., pág. 17 y en concreto nota 17.

18 Insistiendo en la garantía institucional de la autonomía local expresamente referido a las diputaciones provinciales reflejando que, «no precisa la Constitución cuáles sean esos intereses ni cuál es el haz mínimo de competencias que para atender su gestión debe el legislador atribuir a la provincia», fundamento jurídico tercero; Pero por tanto, manteniendo esa garantía institucional de hecho, la posterior Sentencia del Tribunal Constitucional 84/1982 de 23 de diciembre, establece en su fundamento jurídico cuatro «los entes locales (municipios y provincias), tienen autonomía constitucionalmente garantizada por la gestión de sus respectivos intereses (artículo 137 de la Constitución española); la determinación de cuales serán esos intereses es obra de la ley que les atribuye consecuencias concretas».

19 Luis COSCULLUELA MONTANER, op. cit., problemática de..., pág. 1.

20 Así al respecto es paradigmático el caso de Andalucía y así José Ignacio MORILLO VELARDE PÉREZ, “Las Diputaciones Provinciales en la Comunidad Autónoma de Andalucía", Revista española de derecho administrativo, núm. 65, 1989 y "La Provincia en el derecho propio de Andalucía", Revista andaluza de administración publica, núm. 33, 1999. 
MARTÍN RETORTILLO ${ }^{21}$, como entidad local. No obstante, dicha discusión no puede significar en ningún caso la existencia de claras referencias constitucionales al ámbito provincial y su prevalencia sobre cualquier otro tipo de estructuración territorial en el ámbito de las comunidades autónomas, toda vez que la jurisprudencia del Tribunal Constitucional, la preserva de transferencias absolutas de competencias y funciones frente a otras entidades, y especialmente frente a las comarcas.

En efecto, la oposición y dualidad comarcas-provincias se produce históricamente desde un origen del pensamiento político catalanista y de otros regionalismos ${ }^{22}$. Ante la crítica a la institución provincial, basada en razones de centralismo y de oponibilidad política, surge fundamentalmente como respuesta la comarca. La comarca referida tanto como entidad natural más cercana al ciudadano, como respuesta específica de las doctrinas catalanistas, aragonesistas y galleguistas contra el poder central.

No obstante, y pese al reconocimiento constitucional de las diputaciones provinciales y de la provincia en sí como entidad territorial, debemos señalar la existencia, tal y como expresa concretamente MARTíN-RETORTI$\mathrm{LLO}^{23}$, de una auténtica animadversión frente a las corporaciones provinciales ya desde el mismo momento de la elaboración de la Constitución. Pese a ello y dado la absoluta indisponibilidad de la institución provincial, debemos señalar, tal y como afirma FONT I LLOVET ${ }^{24}$, que si la sustantividad de la entidad provincial en cuanto a sus contenidos funcionales queda seriamente afectada por el conjunto de legislaciones autonómicas, y así podemos citar las de Andalucía 25 , Cataluña, Galicia y específicamente la Ley Valenciana de 1983 interpretada por el Tribunal Constitucional en su Sentencia $27 / 1987$, de 27 de febrero, no es menos cierto que desde el punto de vista organizativo las provincias asumen una nueva significación. Como niveles directamente estructurantes el entramado administrativo de la comunidad autónoma, porque junto al movimiento ascendente de centralización de las Diputaciones provinciales se prevén los mecanismos de recuperación de su presencia externa a través de las vías de delegaciones de las competencias autonómicas. Dicha segunda vertiente, ya diseñada en no pocos Estatutos de Autonomía, no ha alcanzado, sin embargo, a juicio de FONT I LLOVET ${ }^{26}$, los niveles mínimos de realización satisfactoria a pesar de su regulación en las comunidades autónomas de Cataluña, Galicia, Andalucía y en algunas otras como en Castilla y León y Aragón. Menos eufemísticamente no se ha utilizado nada.

El núcleo constitucional de las Comarcas se desarrolla fundamentalmente en los Estatutos de Autonomía, debiéndose tener especialmente en cuenta la previsión de la Ley 7/1985, de 2 de abril, Reguladora de las Bases de Régimen Local por las disposiciones de sus artículos 3.2 y 42 que establecen la legislación básica estatal sobre entidades comarcales, determinando su necesidad de creación por la legislación autonómica interpretados por la STC 214/198927.

La Constitución, por tanto, no establece un modelo dispositivo en materia de Comarcas toda vez que el término ni se nombra, pero tampoco impide expresamente la creación posterior de las citadas organizaciones territoriales que son de carácter volitivo toda vez que lo especificado por los artículos 141.3 y 152.3 de la Ley fundamental no prohíbe, pero tampoco obliga la creación de Comarcas. Aunque por su parte ENTRENA CUESTA ${ }^{28}$ señala que el problema de los entes integrantes de la Administración Local no ha sido resuelto por la Constitución Española con la claridad deseable.

21 Sebastián MARTíN-RETORTILLO BAQUER, La provincia, pasado, presente y futuro. Civitas 1991.

22 Acerca del pensamiento regionalista de Alfredo Brañas, véase la biografía de éste de Ramón MAÍZ, Galaxia Editorial, 1986. Santiago de Compostela de Vicente Risco una aproximación al su pensamiento y en general del nacionalismo gallego, lo tenemos en Santiago ÁLVAREZ, "Ensaio encol do problema nacional galego", Anual Editor, 1976, así como Francisco BOBILLO, Nacionalismo galego. La ideología de Vicente Risco, Akal Universitaria, 1981.

23 Sebastián MARTíN-RETORTILLO BAQUER, La provincia, pasado, presente y futuro, op. cit., pág. 96.

24 Tomás FONT I LLOVET, “La comarca y la estructura del gobierno local”, pág. 281 de La Provincia en el sistema constitucional. Diputación de Barcelona. Civitas 1993.

25 Al respecto vid. Antonio JIMÉNEZ-BLANCO CARRILLO DE ALBORNOZ, "La Provincia virtualidad y fortalecimiento en territorio andaluz", Revista andaluza de administración publica, núm. 43/2001.

26 Tomas FONT I LLOVET, “El gobierno local en la reforma del Estado de las autonomías”, Anuario del Gobierno Local, núm. 1, 2004, págs. 1340.

27 La interpretación del parágrafo cuarto del citado artículo 42 señaló por parte del Constitucional «Quiere decirse, pues, que la creación de comarcas podrá repercutir en las competencias de los municipios agrupados en las mismas, pero tal hecho no puede en ningún caso desembocar en una abolición, por desapoderamiento total, de la autonomía municipal constitucionalmente garantizada. A ello se dirige este párrafo $4 .^{\circ}$ del artículo 42, garantizado ese mínimo, sin que pueda imputarse al legislador estatal una extralimitación en el ejercicio de sus competencias determinante de la vulneración, por invasión, del ámbito competencial de las Comunidades Autónomas recurrentes.».

Fija aquí su doctrina el Tribunal Constitucional ya partiendo de la Sentencia 32/1981, de 8 de julio, que estableció que «cabe el reconocimiento, pues, que de la creación de nuevas entidades necesariamente ha de repercutir en la redistribución de los niveles competenciales existentes, pero reconocimiento, también, de que esa readecuación competencial no puede ser a costa de eliminar las competencias de las entidades cuya autonomía queda garantiza.».

28 Rafael ENTRENA CUESTA, “El marco constitucional para la ordenación de la Comarca”, pág. 24 de La Comarca como Ente territorial. Generalitat de Cataluña, 1984 (Barcelona). 
ENTRENA CUESTA ${ }^{29}$ abunda en la distinción anteriormente descrita en la relación con el artículo 152.3 con respecto al precepto del artículo 141.3 del Texto constituyente manteniendo la teoría de que la preocupación del constituyente era a su juicio consagrar en la Constitución la posibilidad de que por vía estatuaria las Comunidades Autónomas de vía especial decidiesen la creación de unos entes territoriales intermedios entre el municipio y la provincia, y cuya existencia habría de ser respetada por el legislador ordinario, siendo según el referido autor ese el sentido de la enmienda «in voce» presentada por el Señor Raventós Carner. Conforme la referida interpretación las «agrupaciones de municipios diferentes a la provincia» previstas en el artículo 141.3 podrán o no creerse a través tan sólo de la legislación básica estatal prevista por el artículo 149.1.18. a , mientras que las circunscripciones propias compuestas por agrupaciones de municipios del artículo 152.3 estarán previstos en los Estatutos y por tanto serán indisponibles por el legislador ordinario estatal que deberá respetarlos (Lo cual al parecer respeta la LRSAL con la redacción sobre el sistema institucional autonómico). La base por tanto de las Comarcas en el texto constitucional es según Entrena Cuesta ${ }^{30}$ la del artículo 152.3 y no la del artículo 141.3 que se refiere tan solo a «agrupaciones de municipios» Junto a la opinión de los autores citados la principal fuente hermenéutica en relación con la naturaleza de las Comarcas es la Jurisprudencia del Tribunal Constitucional. Como consecuencia de la doctrina del TC ${ }^{31}$, tal y como afirman RODRíGUEZ ARANA y RAPOSO ARCEO, citando a JIMÉNEZ BLANCO ${ }^{32}$ la Ley Reguladora de Bases de Régimen Local se vería así reducida a ser una mera ley reguladora de municipios y provincias, quedando las restantes entidades, y especialmente las comarcas, en manos exclusivamente de las Comunidades Autónomas, lo cual a juicio de los citados autores no parece admisible, toda vez que aquellas sólo tienen pleno sentido en relación con los municipios o las comarcas.

Por su parte el Tribunal Constitucional fijó nuevamente su posición en la Sentencia de 12 de noviembre de 1993 en relación con el recurso de inconstitucionalidad planteado por el Gobierno de la Nación en relación con determinados preceptos de la Ley del Parlamento Catalán 8/1987, de 15 de abril, municipal y del régimen local de Cataluña.

Como colorario de la referida doctrina del Tribunal Constitucional es reseñable la Sentencia 48/2004, de 25 de marzo, En ese sentido MEDINA GUERRERO ${ }^{33}$ señala en la que por otra parte junto, a la explicación de la quiebra de la suficiencia del Tribunal Constitucional desarrolla un segundo orden de razonamiento que conduce a que la comisión del artículo 12 de la Ley 5/87 dentro de una limitación indebida de la suficiencia financiera de las Diputaciones Provinciales. De hecho nuestra doctrina generalista, y así Nieves BORREGO ${ }^{34}$ no considera al nivel comarcal dentro de los Entes locales a financiar por el Estado.

EI TC ha remarcado la necesidad de respeto a municipios y provincias. Ahora bien el alcance de la legislación básica pese a dichos conceptos es polémico en relación con el ámbito de las Comarcas, así debemos señalar que por ejemplo PRATS I CATALÁ 35 señala que la legislación contenida en la LRBRL, no realiza diferencias entre los artículos 141.3 y 152.3 de la Carta Magna. No obstante la opinión señalada por Prats de Entrena se sitúa en el año $1984^{36}$ que la distinción que realiza el referido autor sobre competencia legislativa sobre el régimen local de las Comunidades Autónomas entre las Comunidades que deben ejercer dicha competencia dentro del marco del artículo

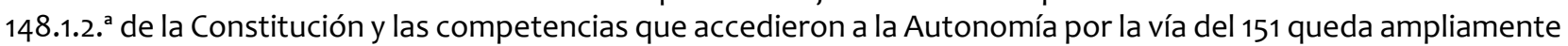
desfasado por el transcurso del tiempo, toda vez que tras el Pacto Autonómico del año 1992 y las Leyes Orgánicas de Transferencias y reformas estatutarias, la totalidad de las Comunidades Autónomas asumieron la capacidad legislativa de desarrollo de las bases de régimen local estatal para sus territorios.

29 Rafael ENTRENA CUESTA, op. cit., pág. 26.

30 Rafael ENTRENA CUESTA, “La Comarca”, págs. 56-57 de La Comarca y la Administración territorial, Centro de Estudios municipales y de cooperación interprovincial (CEMCI), Granada, 1986.

31 En la STC 214/1989, Fundamento Jurídico Cuarto, que analiza el artículo $4 .{ }^{\circ} .2$ de la LRBRL se señala la inconstitucionalidad de las apreciaciones sobre comarcas por parte del Estado, puesto que tal y como se recogía en la ya referida STC 179/85, de 19 de diciembre, Fundamento Jurídico Segundo, el Estado viene a incidir sobre unas entidades que sólo las Comunidades Autónomas pueden crear y en las cuales el citado fundamento de la STC 214/89 afirma el Tribunal Constitucional: «Se trata, en consecuencia, de unas Entidades con un fuerte grado de "interiorización" autonómica por lo que, en la determinación de sus niveles competenciales, el Estado no puede sino quedar al margen. Corresponde, pues, en exclusiva a las Comunidades Autónomas determinar y fijar las competencias de las Entidades locales que procedan a crear en sus respectivos ámbitos territoriales. Asignación de competencias que, evidentemente, conllevará una redistribución, si bien con el límite de que esa reordenación no podrá afectar al contenido competencial mínimo a estas últimas garantizado como imperativo de la autonomía local que la Constitución les reconoce, garantía institucional que, sin embargo, no alcanza "a las Entidades Territoriales de ámbito inferior al municipal”.».

32 Jaime RODRÍGUEZ ARANA, “Estudios de Derecho Local”, Montecorvo, 1997, pág. 198. Estudio sobre notas sobre la funcionalidad de las comarcas, obra conjuntamente realizada con Juan José RAPOSO ARCEO.

33 Manuel MEDINA GUERRERO, La protección constitucional de la autonomía financiera de los Entes locales frente a las alteraciones de su ámbito competencial, Fundación Democracia y Gobierno Local, serie Claves del Gobierno Local III. Barcelona, 2004, pág. 123 y siguientes.

34 J. NIEVES BORREGO, "La financiación de los Entes locales" en Organización territorial del Estado. Administración Local, Instituto de Estudios Fiscales, Madrid, 1985, pág. 223 y siguientes.

35 Joan PRATS I CATALÁ, “La Comarca”, Capítulo XVIII de Tratado de Derecho municipal, Civitas, obra colectiva dirigida por Santiago MUÑOZ MACHADO, 1. ${ }^{a}$ edición, 1988, pág. 822.

36 Rafael ENTRENA CUESTA, “El marco constitucional para la ordenación de la Comarca”, dentro de La Comarca como ente territorial, Generalitat de Cataluña. Escuela de Administración Pública de Cataluña, 1984. Barcelona. 
Por su parte ESTEVE PARDO ${ }^{37}$ señala que el Tribunal Constitucional puede fiarlo todo a lo que disponga la LRBRL referido al ámbito competencial de Comarcas y garantía institucional en relación con entes locales por parte del Estado, invocando a tal efecto la función constitucional encomendada al legislador estatal de garantizar los mínimos competenciales, que dotan de contenido y efectividad a la garantía de autonomía local, y refriéndose al artículo 2 de la Ley Básica destaca su función garantista de las competencias mínimas de las autonomías locales.

En este sentido debemos señalar que la operatividad del artículo 152.3 de la Carta Magna, que posibilita a los Estatutos de Autonomía, en principio previsto para el 151, pero que se ha generalizado al resto de ellos, la capacidad de las comunidades autónomas de establecer una organización territorial de carácter comarcal, basada en la agrupación de municipios, no contradice la referencia constitucional a la existencia necesaria de las referidas diputaciones provinciales, en este aspecto significativo, tal y como señalara Sebastián MARTÍN RETORTILLO ${ }^{38}$, que el reconocimiento de los términos recogidos en el artículo $5 .^{\circ}$ del antiguo EAC de 1979, se hace precisamente a la organización territorial de Cataluña en municipios y comarcas, así como en demarcaciones supracomarcales. Siendo válida esa referencia en el actual Estatuto de 2006 a municipios y Veguerías, pero nunca a provincias., pero con el consabido resultado desde la STC 31/2010.

Fruto de este compromiso consensual es la redacción del artículo 152.3 de la Carta Magna que considera a esas «agrupaciones de municipios» que pueden crear las Comunidades Autónomas como circunscripciones propias y sin embargo las otorga «plena personalidad jurídica» hecho este contradictorio al menos semánticamente puesto que la forma tradicional, circunscripción, se requiere con demarcaciones sin personalidad de una entidad en las cuales se integren.

No obstante antes de abordar la definitiva plasmación de la realidad supramunicipal de carácter no provincial dispuesta por la Constitución y así tal y como señala FERREIRA FERNÁNDEZ ${ }^{39}$, opiniones como la de Sebastián MARTÍN RETORTILLO ${ }^{40}$ y los grupos parlamentarios de UCD y AP plasmaron la realidad.

Ya el Tribunal Constitucional en su Sentencia $27 / 1987$, de 27 de febrero, fundamento jurídico $2 .^{\circ}$, precisó ${ }^{41} \mathrm{La}$ concreta configuración de la autonomía provincial corresponde al legislador básico estatal, incluyendo la especificación del ámbito material de competencias de la entidad local, así como las fórmulas e instrumentos de relación con otras entidades públicas y el sistema de controles de legalidad constitucionalmente legítimos. El Tribunal Constitucional ha considerado perfectamente incluido dentro del ordenamiento jurídico la capacidad de las comunidades autónomas para coordinar las competencias provinciales por parte de las referidas entidades autonómicas, así la vía por la que optó la Comunidad Valenciana anteriormente comentada, e incluso la vía de la ley catalana $5 / 1987$ de régimen provisional de las competencias de las diputaciones provinciales. Dicha ley realiza, a juicio del reiteradamente citado MARTíN RETORTILLO ${ }^{42}$, una reserva del núcleo esencial de funciones objeto de la garantía institucional, que resulta casi inviable o al menos de una complejidad extrema el compaginar las funciones provinciales señaladas en la ley con las que el artículo 82.2 de la Ley 8/87 de ordenación comarcal asignó a la comarca.

Nuestra posición es claramente defensora ${ }^{43}$ de las diputaciones provinciales no solo por ampararnos en su garantía institucional declarada por el Tribunal constitucional, sino en la base a que una acertada estructuración de los servicios territoriales de las Comunidades Autónomas o una correcta simplificación de la administración

37 José ESTEVE PARDO, Organización supramunicipal y sistema de articulación entre Administración autonómica y orden local. La experiencia de la RFA. Bases y perspectivas en España, Civitas, 1991, págs. 192 y 193.

38 Sebastián MARTÍN-RETORTILLO BAQUER, op. cit., La provincia: pasado, presente y futuro, pág. 112.

39 FERREIRA FERNÁNDEZ Antonio Javier, El Régimen jurídico de la Comarca en el sistema autonómico español, págs. 46 a 49. Cedecs, Barcelona, 1999. Así en el texto del Anteproyecto de Constitución se recogía dentro de la regulación dedicada a «La Administración» del capítulo II del Título IV disponía en el artículo 105, párrafo segundo: «Las provincias, o en su las circunscripciones que los Estatutos establezcan mediante la agrupación de municipios, gozarán igualmente de plena personalidad jurídica y servirán de base a la organización territorial de la Administración pública, sin perjuicio de otras formas de división establecidos por la ley con este fin.».

La reacción política y doctrinal frente a dicha redacción, que hubiese supuesto en la práctica dos divisiones territoriales salvo adaptación del sistema estatal provincial a la estructura que diseñaran las Comunidades Autónomas, generó lo que FERREIRA FERNÁNDEZ denomina giro radical en el texto del anteproyecto sustentado por

40 La cerrada defensa del autor citado de la institución provincial cristaliza ya desde la critica al referido anteproyecto de Constitución y así Sebastián MARTíN-RETORTILLO BAQUER, "Las Corporaciones Locales en el Anteproyecto de la Constitución", Revista de Estudios de la Vida Local (Actual Revista de Estudios de la Administración Local y autonómica), núm. 179, 1978, pág. 11 y siguientes, donde plantea expresamente que la redacción dispuesta, además de entremezclar determinaciones de la Administración del Estado con la Administración Local plantea la posibilidad de que desaparezcan las provincias y se sustituyan por una organización comarcal.

41 Al señalar que «la Constitución garantiza la autonomía de las provincias para gestión de sus propios intereses, artículo 137, encomendando su gobierno y administración a diputaciones y otras corporaciones de carácter representativo, artículo 141.2, como este Tribunal ha precisado en repetidas ocasiones».

42 Sebastián MARTíN-RETORTILLO BAQUER, op. cit., “La provincia...”, pág. 119.

43 Así compartiendo en buena parte las tesis del difunto Sebastián Martín-Retortillo, discrepamos del modelo antiprovincialista que subyace de la exposición realizada por CARBALLEIRA RIVERA, María Teresa “¿Se han convertido las provincias en un simple nombre?”, en Revista de Estudios de la Administración Local, núm. 289, mayo-agosto, 2002, págs. 9 a 36. 
descentralizada en base a las posibilidades otorgadas desde la ley 12/1983 reguladora del proceso autonómico, la mantienen como entidad esencial.

Por ello deberemos señalar un límite y hasta una innecesariedad de las organizaciones comarcales en las comunidades autónomas de carácter pluriprovincial, sin perjuicio de sus lógicas competencias en uso de su potestad de autoorganización, ya que todo el ámbito de entidad local supramunicipal, tanto en el caso de dicha autoorganización, como de aplicarse los criterios de simplificación administrativa, como el de demarcación territorial para la consecución de los fines de la administración autonómica, están suficientemente cubiertos, al menos en los casos generales, por las diputaciones provinciales.

En la actualidad existen en el territorio nacional dos modelos comarcales que coexisten con las diputaciones provinciales, son los casos catalán y aragonés,, pero en los cuales podemos distinguir la superposición de funciones entre unos y otras entidades, por lo que en buena línea podía tener vigencia la opinión del profesor Martín Retortillo al respecto, aunque en el caso Catalán el modelo comarcal tiene una cierta tendencia a su fagocitación por las Veguerias ${ }^{44}$. De hecho ambos modelos se consagran con la reforma «racionalizadora» de 2013.

\section{I.4. La LRSAL y el papel de las provincias 45}

Con la famosa Ley 27/2013, de 27 de diciembre, de racionalización y sostenibilidad de la administración local, es importante tener en cuenta que la fórmula de la remisión que hacia la antigua redacción del art. 3.2 a la legislación básica, en relación con la creación de comarcas u otras entidades que agrupen municipios, a través de un procedimiento concreto desaparece y aunque es una variación muy semántica, puesto que se mantiene la redacción de los arts. 42 a 44 LRBRL y la referencia a los correspondientes estatutos de autonomía con respecto a las comarcas, u otras entidades que agrupen varios municipios instituidas por las Comunidades Autónomas, se consagra una mayor interiorización de estas entidades, ya no solo para el caso de las comarcas catalanas, ya excepcionadas por la redacción original de la LRBRL, sino con un carácter general, seguramente vinculado al caso de Aragón, lo que no es seguramente ajeno al pacto PP-PAR en dicha Comunidad en esa legislatura ${ }^{46}$.

El art. 26 LRBRL fue nuevamente redactado en virtud de la enmienda $414^{47}$, del Congreso. De hecho hay quien califica esta técnica, como CASTILLO BLANCO ${ }^{48}$, como una mutación de las diputaciones. Dentro del modelo que se plantea es clave lógicamente la nueva articulación de las funciones y competencias de la Diputación Provincial, en ese sentido el art. 36 de la LRBRL queda modificado en su redacción actual por el apartado decimotercero del

44 Acerca de las veguerías debe consultarse la obra de Ricard GRACIA RETORTILLO, La veguería como gobierno local intermedio en Cataluña. Editorial Huygens, 2008. Barcelona.

45 La ley ha sido objeto de diversos estudios y así por orden cronológico "La reforma de 2013 del régimen local español", Fundación Democracia y Gobierno Local, 2014, obra colectiva coordinada por Juan Alfonso SANTA MARÍA PASTOR, “La reforma del régimen jurídico de la administración local. El nuevo marco regulatorio a la luz de la ley de racionalización y sostenibilidad de la administración local” obra colectiva coordinada por Juan Antonio CARRILLO DONAIRE y Pilar NAVARRO RODRÍGUEZ, La ley-El Consultor, 2014, igualmente colectiva y dirigida por Tomás QUINTANA LÓPEZ, “La reforma del régimen local. Comentario a la ley 27/2013, de 27 de diciembre, de racionalización y sostenibilidad de la administración local”, Tirant lo Blanch, 2014. Igualmente Lorenzo MELLADO RUIZ, "Génesis y realidad de la ley 27/2013, de 27 de diciembre, de racionalización y Sostenibilidad de la administración local: ¿una nueva reforma local?”, CEMCI 2014, Manuel MEDINA GUERRERO, "La reforma del régimen local”, Tirant lo Blanch, 2014, CAMPOS DAROCA, José María, “La reforma de la Ley de bases de régimen local: Ley 27/2013, de 27 de diciembre", BOSCH, 2014 y CEBRIÁN ABELLÁN, Manuel, "El régimen local tras la reforma de la Ley de racionalización y sostenibilidad”, BoschWolters Kluwer, 2014.

46 No obstante en el trámite del Senado los senadores del PAR integrados en el grupo Popular presentaron numerosas enmiendas «por libre».

47 Pág. 287 BOCG de 30 de octubre de 20132. En los municipios con población inferior a 20.000 habitantes será la Diputación provincial o entidad equivalente la que coordinará la prestación de los siguientes servicios:

a) Recogida y tratamiento de residuos. b) Abastecimiento de agua potable a domicilio y evacuación y tratamiento de aguas residuales.

c) Limpieza viaria.

d) Acceso a los núcleos de población.

e) Pavimentación de vías urbanas.

f) Alumbrado público.

Para coordinar la citada prestación de servicios la Diputación propondrá, con la conformidad de los municipios afectados, al Ministerio de Hacienda y Administraciones Públicas la forma de prestación, consistente en la prestación directa por la Diputación o la implantación de fórmulas de gestión compartida a través de consorcios, mancomunidades u otras fórmulas. Para reducir los costes efectivos de los servicios el mencionado Ministerio decidirá sobre la propuesta formulada que deberá contar con el informe preceptivo de la Comunidad Autónoma si es la Administración que ejerce la tutela financiera.

Cuando la Diputación o entidad equivalente asuma la prestación de estos servicios repercutirá a los municipios el coste efectivo del servicio en función de su uso. Si estos servicios estuvieran financiados por tasas y asume su prestación la Diputación o entidad equivalente, será a ésta a quien vaya destinada la tasa para la financiación de los servicios.

Cuando la Diputación o entidad equivalente acredite en un informe, a petición del municipio, que éste puede prestar estos servicios con un coste efectivo menor que el derivado de la forma de gestión decidida por la Diputación provincial o entidad equivalente, el municipio podrá asumir la prestación y coordinación de estos servicios.». 
art. 1 de la ley sobre racionalización y sostenibilidad de la administración local, atribuyéndose en primer lugar la competencia sobre coordinación de los servicios municipales obligatorios, para la garantía de la prestación integral y adecuada de lo previsto en el apartado del art. 31.2 LRBRL, haciéndose coincidir en buena lógica sistemática con la regulación de los servicios obligatorios del art. 26.2.

En dicha línea debemos destacar la existencia por tanto de un nivel de servicios de carácter supramunicipal y en su caso supracomarcal, atribuido a las Diputaciones Provinciales en su prestación, conforme a la determinación del art. 36.1 c de la LRBRL, así como el fomento o en su caso, tal y como especifica expresamente la ley de la coordinación de la prestación unificada de servicios de los municipios en sus respectivo ámbito territorial, por tanto debemos destacar el nuevo papel de la Diputación como prestadora de servicios directos, así como de entidades de cooperación, colaboración y en muchos casos de supervisión de la actividad municipal. La redacción final incorporó la enmienda en el congreso 415 del grupo popular ${ }^{49}$.

Por otra parte, y tal y como indica FUERTES LÓPEZ ${ }^{50}$, se recogen otras funciones más precisas y alineadas, todas ellas, con los principios de eficiencia, estabilidad y sostenibilidad financiera y el garantizar un control financiero y presupuestario más riguroso, lo que ha sido calificado como antidemocrático por algún grupo de la entonces oposición ${ }^{51}$.

Ahora bien no podemos hablar tan solo de Diputaciones Provinciales desde el punto de vista de únicos gestores de las provincias como entidad local, puesto que la LRSAL en su disposición adicional tercera recoge la posibilidad de desaparición de estas figuras, al menos en Comunidades Autónomas concretas, puesto que remite de forma expresa en el punto 2 de dicha disposición adicional segunda a los sistemas institucionales propios de las Comunidades Autónomas que los cuenten, o que cuenten con ellos con una referencia a que las alusiones a las Diputaciones se entenderán efectuadas a los entes locales supramunicipales previstos en los correspondientes Estatutos de Autonomía a los que se atribuyen competencias en materia de asistencia y cooperación a los municipios y prestación de servicios públicos locales, lo que genera un espacio para las comarcas y veguerías y que el FJ 3 de la STC 168/2016, de 6 de octubre, interpreta conforme a la Constitución.

La verdadera novedad y no pacífica desde luego ${ }^{52}$, en materia supra municipal de la ley con respeto a la legislación vigente es la coordinación en la prestación de los servicios de carácter obligatorio para los municipios de menos de 20.000 habitantes prevista tras la nueva redacción del art. 26 apartado 2 y $3^{53}$. Otra fórmula de coordina-

48 Federico CASTILLO BLANCO, Diario de derecho municipal, 3 de enero de 2014, "Una lectura de urgencia de la ley $27 / 2013$, de 27 de diciembre de racionalización y sostenibilidad de la administración local".

49 (Pág. 288, BOCG 30 de octubre de 2013). «Trece. El artículo 36.1 queda redactado como sigue:

1. Son competencias propias de la Diputación o entidad equivalente las que le atribuyan en este concepto las leyes del Estado y de las Comunidades Autónomas en los diferentes sectores de la acción pública y, en todo caso, las siguientes:

c) La prestación de servicios públicos de carácter supramunicipal y, en su caso, supracomarcal y el fomento o, en su caso, coordinación de la prestación unificada de servicios de los municipios de su respectivo ámbito territorial. En particular, asumirá la prestación de los servicios de tratamiento de residuos en los municipios de menos de 5.000 habitantes, y de prevención y extinción de incendios en los de menos de 20.000 habitantes, cuando éstos no procedan a su prestación.».

50 Javier FUERTES LÓPEZ, La reforma de la Ley de Bases de Régimen Local Del Anteproyecto de Ley de Reforma y Sostenibilidad de la Administración Local a su tramitación parlamentaria, E-Book. El Derecho.com, Francis Lefevbre 2013.

51 Así en su enmienda a la totalidad el grupo de UPyD, Boletín Oficial de las Cortes Generales, Congreso de los diputados, 30 de octubre de 2013, pág. 18, enmienda núm. 6 y en concreto, págs. 18 y 19 se reseña: «El proyecto de Ley no respeta los valores democráticos ya que deja vacíos de funciones a los ayuntamientos que eligen los ciudadanos mientras refuerza unas Diputaciones, que mantiene como órganos infra democráticos al conservar su sistema de elección indirecta de segundo grado. De esta forma, los representantes municipales que deben rendir cuentas ante los ciudadanos no gestionarán nada y quienes gestionan no rendirán cuentas ante los ciudadanos sino ante los partidos que les hayan designado. Los alcaldes y concejales sin apenas poder decisorio quedarán como mediadores de los intereses vecinales con el poder no electivo de la Diputación, un papel que no puede describirse sino como clientelismo y neo caciquismo. Esto creará el caldo de cultivo institucional perfecto para más partitocracia, despilfarro y corrupción.».

52 Sirva de ejemplo la enmienda núm. 367 (pág. 263), en el congreso del grupo CiU que señala: El artículo 26 elimina por completo el principio de autonomía local, puesto que vacía a los municipios de menos de 20.000 habitantes de la capacidad de decisión del consistorio, democráticamente elegido, para pasar la gestión de las competencias municipales a las diputaciones, lo cual contraviene el artículo 140 de la Constitución, el cual mandata que el gobierno y administración de los municipios «corresponde a sus respectivos Ayuntamientos, integrados por los Alcaldes y Concejales.».

A la objeción al propio modelo, cabe añadir la profunda inseguridad jurídica resultante de un sistema en que toda decisión se deja al arbitrio de las diputaciones y se restringe la capacidad de los ayuntamientos para la defensa de la prestación de sus servicios, a la demostración en términos comparativos de una mejora de costes, que en ningún caso se dice si deben ser considerados de forma conjunta o individualizada, en relación al catálogo que contiene el propio precepto.

Finalmente, el hecho que la asunción de la prestación de servicios municipales y la plena capacidad de decisión sobre los mismos recaiga en una administración no sujeta, en cuanto a su composición, a mecanismos de elección directa y al margen de la organización territorial que establece el EAC, hace que el modelo de la reforma, en su conjunto, merezca su reprobación.

53 La cual supone que la Diputación propondrá con la conformidad eso si de los municipios con respecto al texto originario del anteproyecto de ley las fórmulas para la prestación de esos servicios aunque es el Ministerio el que decide con informe de la Comunidad Autónoma también prevé que la Diputación debe acreditar en un informe a petición de un municipio que se puede eximir de dicha coordinación en el supuesto que el servicio prestado por el municipio tenga un coste efectivo menor que su integración o coordinación a nivel provincial. 
ción atribuida a las diputaciones es la incorporada mediante la enmienda núm. $411^{54}$ referida a Una intervención de las Diputaciones que lógicamente debe de entenderse en el caso de las Comunidades Autónomas uniprovinciales referido a las Comunidades Autónomas.

Esta figura expuesta por COSCULLUELA MONTANER ${ }^{55}$ y reiteradamente analizada por el Tribunal Constitucional ${ }^{56}$ La coordinación puede concretarse, tal y como afirma HINOJOSA MARTíNEZ ${ }^{57}$, para aquellas relaciones que presididas por la potestad incluida a una de las administraciones, fundamentalmente entendemos nosotros la coordinadora, con respeto a la autonomía local consideradamente garantizada, tienen por finalidad la integración de las partes o sus sistemas en el conjunto unitario a través de la fijación de medios y sistemas de relación interadministrativos. Tal modalidad de coordinación no es, tal y como se ha encargado de mostrar JIMÉNEZ I CORRONS ${ }^{58}$, una relación de control al menos en ese sentido estricto.

\section{LA ORGANIZACIÓN TERRITORIAL DE LAS ADMINISTRACIONES AUTONÓMICAS}

\section{II.1. Características generales}

En cuanto a las características de la organización territorial propia de cada Comunidad y con el ya referido ARGULLOL ${ }^{59}$, hay que destacar que una lectura de los distintos Estatutos permite distinguir, como ya hemos indicado, entre las Comunidades Autónomas en las que no se prevé una opción a favor de sistemas de administración indirecta y aquellas en las que los Estatutos optan expresamente por sistemas de administración indirecta. Esta circunstancia en su momento era de gran importancia , tanto por las recomendaciones del grupo de expertos presidido por el profesor García de Enterría, como por la propia LOAPA, pero la STC 76/1983 lo impidió.

La reacción política y doctrinal frente a dicha redacción, que hubiese supuesto en la práctica dos divisiones territoriales salvo adaptación del sistema estatal provincial a la estructura que diseñaran las Comunidades Autónomas, generó lo que FERREIRA FERNÁNDEZ ${ }^{60}$ denomina giro radical en el texto del anteproyecto sustentado por sobre esta y la praxis de las CC.AA, han dejado esta clasificación en pura teoría pese a la vigencia de la Ley del Proceso Autonómico. De hecho, las diputaciones fueron los embriones, o por lo menos entes propiciadores, de los procesos autonómicos, tal y como se deriva del artículo 143 de la Constitución, y como han señalado Sebastián Martín Retortillo, en las obras citadas y por otra parte MORELL OCAÑA ${ }^{61}$.

Aparte quedaría el caso de la Comunidad Autónoma Vasca, cuyas peculiaridades forales conllevan una determinada construcción del papel de las entidades locales de orden provincial.

Por lo que respecta a las comunidades autónomas, la cuestión de la Administración periférica no se plantea sólo en términos del papel político más o menos importante que juega el nivel provincial como división territorial, sino que además se plantea la posibilidad de que las comunidades autónomas pluriprovinciales utilicen las estructuras burocráticas de la Administración provincial y local para la gestión de asuntos de su interés.

Aunque tal posibilidad fue apuntada en el Informe de la Comisión de Expertos sobre Autonomías en 1981, los casos en que las comunidades autónomas se han apoyado en las diputaciones son casi excepcionales (tal vez, pueda apuntarse Castilla y León, y sólo en un primer momento).

Lo cierto es que lo que se ha generalizado ha sido un modelo de Administración periférica que reproduce exactamente el que tenía el Estado central. Es decir, un fuerte núcleo centralizado de la Administración propia de cada comunidad autónoma que se ramifica luego en todo el territorio al que extiende sus competencias. Para

54 (pág. 286) del grupo parlamentario popular El artículo 36.1 queda redactado como sigue:

"1. Son competencias propias de la Diputación o entidad equivalente las que le atribuyan en este concepto las leyes del Estado y de las Comunidades Autónomas en los diferentes sectores de la acción pública y, en todo caso, las siguientes:.../

i) La coordinación mediante convenio, con la Comunidad Autónoma respectiva, de la prestación del servicio de mantenimiento y limpieza de los consultorios médicos en los municipios con población inferior a 5000 habitantes.».

55 Luis COSCULLUELA MONTANER, Manual de derecho administrativo, pág. general, 27. edición, Civitas-Thomson Reuters 2016, pág. 201.

56 Así en sus sentencias 32/1983, de 28 de abril, 42/1983, de 20 de mayo, 76/1983, de 5 de agosto, 11/1984, de 2 de febrero, y 144/1985, de 25 de octubre, entre otras.

57 Eduardo HINOJOSA MARTÍNEZ, "Las relaciones entre la administración local y demás administraciones públicas", capítulo 3. de Tratado de Derecho Loca, Thomson-Aranzadi, obra colectiva dirigida por Tomas COBO OLVERA, 2010 y en concreto págs. $241-242$.

58 Eva JIMÉNEZ I CORRONS, Los controles administrativos sobre los entes locales, Marcial Pons-Generalitat de Cataluña-Instituto de estudios autonómicos, 2001.

59 Enric ARGULLOL, op. cit., págs. 107-110.

60 Antonio Javier FERREIRA FERNÁNDEZ, op. cit., pág. 48.

61 Luis MORELL OCAÑA, “Configuración y ordenación territorial de las Comunidades Autónomas”, publicado en la Revista de Derecho Administrativo, núm. 31. Civitas. 
la provincia como entidad autónoma, tal realidad tiene sin duda una lectura negativa, ya que las comunidades autónomas han preferido un sistema propio de delegaciones ${ }^{62}$, descartando así una importantísima fuente de funciones a desarrollar.

Esta habilitación lo era también para las islas en su condición de entidad local de segundo grado en los archipiélagos balear ${ }^{63}$ y Canario $^{64}$.

\section{II.2. Derterminaciones originarias de carácter autonómico}

En la referencia al ámbito supramunicipal vasco, tal y como señala ROCA ROCA ${ }^{65}$ afirmando que el artículo 37.3 de dicho Estatuto remite a los órganos forales de los territorios históricos la competencia exclusiva, dentro de cada uno de estos, entre otras materias de las demarcaciones territoriales de ámbito supramunicipal que no excedan de los límites provinciales lo cual serían las Comarca. No se recoge en el artículo $10 .^{\circ}$ del referido Estatuto, dentro de las competencias con carácter exclusivo de la Comunidad Autónoma, más que las demarcaciones municipales por lo que la Comarca quedará referida al 37.3.C) del Estatuto tal y como ha afirmado igualmente RODRíGUEZ SÁEZ ${ }^{66}$. Ahora bien hay autores como FERREIRA FERNÁNDEZ ${ }^{67}$ entienden que dicha competencia no es absoluta que toda vez que esta referida a demarcaciones territoriales de ámbito supramunicipales o demarcaciones supramunicipales, términos estos ambiguos puesto que pueden ser interpretados con una circunscripción territorial periférica de los órganos forales o cualquier otra circunscripción territorial de orden funcional que pudieran crear los territorios históricos.

Dicho argumento no cabe menos que ser considerado temerario toda vez que Las Cuadrillas implantadas en Álava mediante Norma Foral de 20 de noviembre de 1989 tienen personalidad jurídica propia y han sido creadas por el territorio foral de Álava.

En ese sentido tanto la doctrina (LÓPEZ DE JUAN ${ }^{68}$ ) como el propio Tribunal Constitucional ${ }^{69}$ y la propia regulación normativa de los territorios forales ${ }^{70}$ han configurado la capacidad de los territorios históricos para crear entidades de ámbito supramunicipal que serían equiparables a las del artículo 152.3 de la Constitución Española.

En Cataluña el vigente Estatuto de 2006, además de «interiorizar» toda la organización local se elimina a las provincias como parte de la organización catalana (sin perjuicio de las competencias estatales) y se crea la veguería ${ }^{71}$ como entidad local y circunscripción para la prestación de servicios por la Generalitat. Debemos destacar, tal y como se recoge de forma expresa en el fundamento jurídico primero.4 de la STC 103/2013 que el titulo competen-

62 En el caso de Cataluña, por usar el ejemplo más significativo de comunidad autónoma hostil a la provincia y que ha realizado una clara apuesta por la comarca como entidad supramunicipal, el Decreto 280/1986 estableció la estructura organizativa de la Administración territorial de la Generalidad a partir de cuatro delegaciones territoriales del Gobierno de la Generalidad «en las demarcaciones» de Barcelona, Girona, Lleida y Tarragona. Es decir, las cuatro provincias tradicionales; si bien el Decreto 79/2001, de 6 de marzo, creó la Delegación Territorial del Gobierno de la Generalidad en las Terres de l'Ebre, con jurisdicción sobre las comarcas del sur de la provincia de Tarragona y capital en Tortosa. También existen subdelegaciones territoriales y, aunque las cuatro, ahora cinco, demarcaciones son usadas también por el resto de departamentos, en algunos casos (Educación, Sanidad) la división territorial está algo más desagregada. En otras comunidades autónomas existen también delegaciones o subdelegaciones en ciudades importantes que no ostentan la categoría de capital de provincia -Vigo en Galicia, Talavera de la Reina en Castilla-La Mancha o, c, Algeciras en Andalucía- pero se trata de excepciones a una regla muy generalizada que confía en el mapa provincial tradicional.

63 En relación con los Consells es de obligada lectura la obra de Luis COSCULLUELA MONTANER, "El Régimen local y los consejos insulares en el Estatuto Balear de 2007”, págs. 283 a 396 de El gobierno local. Estudios en homenaje al profesor Luis Morell Ocaña. lustel-Cosital. 2010. Obra colectiva coordinada por Alberto RUIZ OJEDA y Luciano PAREJO ALFONSO, "La cuestión de la organización del gobierno y la administración insulares en la Comunidad Autónoma de las Islas Baleares”, Revista de Estudios de la Administración Local, núm. 291, enero-abril de 2003, págs. 891 a 924.

64 Con respecto a los cabildos desde una perspectiva general puede consultarse: Francisco VILLAR ROJAS y Carlos DE LA CONCHA BERGILLOS, "El régimen especial canario", cáp. LXX, tomo IV, de Tratado de derecho municipal, 3. edición. lustel 2011. Obra colectiva coordinada por Santiago MUÑOZ MACHADO, más antiguo sobre el régimen específico de los Cabildos puede analizarse en Joaquín VALLE BENÍTEZ, "Los Cabildos insulares", págs. 69 a 84 de Estudios de derecho Administrativo Especial Canario, dirigidos por Alejandro NIETO. Cabildo Insular de Tenerife, 1967 (reimpresión de 1994).

65 Eduardo ROCA ROCA, "Comarca y Estatutos de Autonomía en la Comarca y la Administración territorial”, Centro de Estudios Municipales y Cooperación interprovincial de las Diputaciones de Almería, Granada, Jaén y Málaga dentro del número 18 de Temas de la Administración Local, 1986, págs. 110 a 137 y en concreto pág. 126.

66 Miguel Ángel RODRÍGUEZ SÁEZ, “Las cuadrillas en el territorio histórico de Álava”, pág. 149 a 164 de la obra colectiva Los espacios de solidaridad territorial con los presupuestos del Pacto Local, Gobierno de La Rioja, 2003, y en concreto pág. 151.

67 Javier FERREIRA FERNÁNDEZ, El régimen jurídico de la Comarca en el sistema autonómico español, op. cit., pág. 61.

68 José Manuel LÓPEZ DE JUAN, “Entidades supramunicipales del País Vasco: Comarcas y Mancomunidades”, en Instituciones de la Comunidad Autónoma de Euskadi, Gobierno Vasco, Oñate, 1982, pág. 267.

69 Sentencia $179 / 1985$, de 19 de diciembre, Fundamento Jurídico 2.․

70 La citada Norma Foral de Cuadrillas alavesa así como la Norma Foral de Vizcaya 3/1995, de 30 de marzo, reguladora de entidades de ámbito supramunicipales.

71 Acerca de las veguerías debe consultarse la obra de Ricard GRACIA RETORTILLO, La veguería como gobierno local intermedio en Cataluña. Editorial Huygens 2008. Barcelona. 
cial asumido, en este caso, por la Generalitat de Cataluña en su Estatuto de Autonomía, aprobado por Ley Orgánica $6 / 2006^{72}$ y en concreto, las competencias de carácter exclusivo sobre régimen local fijadas en el artículo $160.1^{73}$

Las peculiaridades de la organización territorial gallega, que por parte de algunos autores como GONZÁLEZ MARIÑAS ${ }^{74}$, el ya referido FERREIRA FERNÁNDEZ y en menor medida MEILÁN GIL, implica necesariamente la implantación de la Comarca como ámbito para la estructuración territorial de la Xunta. Esto, como se encarga de señalar SOSA WAGNER ${ }^{75}$, implica competencia exclusiva en virtud del título competencial del artículo 27.2 del Estatuto sobre organización y régimen jurídico de las Comarcas,.

Para otros autores como PORTERO MOLINA y MAÍZ SUÁREZ76 el marco legislativo estatal supone a la competencia de la Comunidad Autónoma gallega una capacidad para organizar y determinar el régimen jurídico de las Comarcas con carácter residual dependiendo de la normativa estatal, por lo tanto, evidentemente es una articulación de las Comarcas de carácter local, línea mantenida por la Sentencia del Tribunal Constitucional 214/198977.

En un sentido diferente FERREIRA ${ }^{78}$, CARRO FERNÁNDEZ-VALMAYOR ${ }^{79}$ y MEILÁN GIL ${ }^{80}$ afirman la identificación de la declaración genérica del artículo $2 .^{\circ}$ en cuanto organización territorial con las determinaciones de los artículos 27 y 40 sobre las Comarcas formando en su opinión la Comarca parte de la organización territorial de la propia Xunta.

De hecho hoy en día en Galicia pese a los intentos comarcalizadores no se ha establecido una estructura territorial comarcal, ni mucho menos como Entidad local por el peso importantísimo de las Diputaciones Provinciales tanto político como social en el territorio gallego.

En Andalucía las determinaciones originarias a juicio de Roca Roca ${ }^{81}$ hacía que de las Comarcas en Andalucía sean verdaderos entes locales intermedios ente el municipio y la provincia dotados de autonomía y personalidad jurídica diferente de los municipios La nueva versión del Estatuto, aprobada por Ley Orgánica 2/2007, de 19 de marzo, de reforma del Estatuto de Autonomía para Andalucía, mantiene la línea provincialista del primero, puesto que el territorio de la Comunidad recogido en el art. $2 .^{\circ}$ de este al indicar que el territorio de Andalucía comprende el de los municipios de las provincias de Almería, Cádiz, Córdoba, Granada, Huelva, Jaén, Málaga y SeviIla. Las competencias en la materia que nos ocupa se recogen en los arts. 59 y 60 del nuevo EA y así el artículo 59. Organización territorial.

\section{II.3. Principado de Asturias}

El primero de los Estatutos de Autonomía promulgados por la vía del artículo 143 de la Constitución es el de Principado de Asturias, exactamente aprobado por Ley Orgánica 7/1981, de 30 de diciembre. En la redacción original del artículo 6.1 del citado Estatuto establecía que el Principado de Asturias se organiza territorialmente en municipios que reciban la denominación tradicional de Concejos y en Comarcas. Por su parte el artículo 24.5 de la norma estatutaria remite a la Ley regional la creación de estas Comarcas.

72 Al respecto vid. "La organización territorial en Cataluña tras el estatuto de autonomía de 2006: Tres proyectos ley sobre fondo gris", Joaquín TORNOS MAS, dentro de op. cit. Reforma Estatutaria y régimen local, págs. 121 a 146.

73 Ello no significa, sin embargo, que el título competencial del Estado para la regulación del régimen local se haya visto eliminado por la reforma estatutaria pues, tal y como tenemos señalado en la STC 31/2010, de 28 de junio, las previsiones estatutarias deben respetar en todo caso "la competencia básica que al Estado corresponde en la materia, en virtud de la reserva del art. 149.1.18 CE, por cuanto la expresión base del régimen jurídico de las Administraciones Públicas engloba a las Administraciones Locales» (fundamento jurídico 36). Por lo tanto, la apreciación del art. 160.1 del Estatuto de Autonomía Catalán al reconocer las competencias sobre régimen local con carácter exclusivo, se hace de manera impropia y no impide que sobre dichas competencias autonómicas puedan operar previamente las bases estatales, específicamente las del art. 149.1.18 en los términos que recogía la indicada sentencia del TC 31/2010, de 28 de junio en sus fundamentos jurídicos 60 y 64, tal y como se indica en el fundamento jurídico 100 de la reiterada sentencia 31/2010, de 28 de junio.

74 Pablo GONZÁLEZ MARIÑAS, Territorio e identidade: Galicia como espacio administrativo: a grandes cuestions históricas e sua protxecció a tuar sur de Galicia, Santiago, 1994.

75 Francisco SOSA WAGNER, Comentario al Estatuto de Autonomía Gallego, pág. 338.

76 Juan Antonio PORTERO MOLINA y Ramón MAÍZ SUÁREZ, Las instituciones políticas en el Estatuto de Autonomía para Galicia, Parlamento de Galicia, Santiago de Compostela, 1998, págs. 40 y 41.

77 Que resolvió el recurso de inconstitucionalidad interpuesto por la Xunta de Galicia contra la propia Ley 7/1985 y concretamente contra el artículo 42.2 de la LBRL que en Fundamento Jurídico Decimotercero señala expresamente que «la comarca no se configura como una entidad necesariamente integrante de la organización territorial de la Comunidad Autónoma» poniendo según el Estatuto de Autonomía tan solo la competencia de desarrollo legislativo de las bases estatales para el hecho comarcal en lo dispuesto en los artículos 40.1 y 27.2 del Estatuto.

78 Javier FERREIRA FERNÁNDEZ, op. cit., pág. 91.

79 José Luis CARRO FERNÁNDEZ-VALMAYOR, Comentarios al Estatuto de Autonomía de Galicia, Ministerio de Administraciones Públicas, Madrid, 1991, pág. 46.

80 José Luis Meilán Gil, “Los problemas jurídico-administrativos de la comarcalización en Galicia” Ponencia presentada en las Primeras Jornadas sobre la Comarcalización y Ordenación del Territorio. Santiago de Compostela, 26-27 de febrero de 1988, pág. 19.

81 Eduardo ROCA ROCA, Comarca y Estatutos de Autonomía..., op. cit., pág. 127-128. 
Por tanto en Asturias nos encontramos con dos singularidades: En primer lugar la existencia de una Comunidad Autónoma uniprovincial y en segundo lugar la incorporación a la estructura territorial del Principado a la Comarca, por lo cual nos encontramos con una determinación similar a la dispuesta para Cataluña al menos en el nivel estatutario.

Ese carácter de organización necesaria con carácter de entidad, por lo tanto personalidad jurídica dentro del entramado organizativo de la Comunidad Autónoma de Asturias, ha hecho que autores como López-Medel ${ }^{82}$ hayan equiparado a la determinación del artículo $5 .^{\circ}$ del Estatuto de Autonomía de Cantabria en cuanto al carácter clave de innecesariedad de las Comarcas en el entramado organizativo de la propia Comunidad Autónoma.

Ahora bien a diferencia de la propia Cataluña y de las Comunidades Autónomas anteriormente analizadas, el nivel estatutario y de competencias en el régimen local, al menos hasta las reformas que se produjeron en el año 1998 como consecuencia de los Pactos Autonómicos de 1992 y el inicio de la variación competencial en 1993, implicaba tan sólo el ejercicio de las funciones que pudieran corresponder a la Administración del Estado sobre diversas materias de Régimen Local fundamentalmente las del Texto Refundido de Régimen Local de 1986 y el título habilitante del artículo 148.1.2. ${ }^{a}$ de la propia Carta Magna sobre alteraciones de los términos municipales, función ésta escasa para un desarrollo normativo de la Comarca en cuanto entidad local, pero es base a dicho título y concretamente al previsto en el artículo 11.a) del Estatuto en su redacción originaria En el marco de dicha habilitación estatutaria se promulgo la Ley 3/1986, de procedimiento de creación de Comarcas, ley todavía no desarrollada ni iniciados los procesos comarcalizadores, seguramente puesto que el nivel de promulgación del Estatuto, el deseo comarcal es distante, amplio y seguramente la rebufo de la doctrina y del prestigio que la autonomía catalana gozaba ante el resto de España supuso una implantación de una estructura no debidamente sopesada.

\section{II.4. Cantabria}

El segundo de los Estatutos de Autonomía promulgado por la vía del 143 fue el de Cantabria mediante la Ley Orgánica 8/1981, de 30 de diciembre. Nos encontramos nuevamente con una Comunidad Autónoma uniprovincial desgajada de Castilla y León.

En dicho Estatuto el artículo 23 posibilita la capacidad legislativa en el marco de la legislación básica del Estado la mínima actividad que teníamos para Asturias en el artículo 14.1.2. a , esto es creación de entidades supramunicipales lo cual desarrollará los preceptos del artículo 141.3 de la Carta Magna en relación con el artículo 152.3.

Debemos destacar que el Estatuto cántabro es mucho más ambicioso en cuanto su configuración comarcal que los otros Estatutos de Autonomía de las diferentes Comunidades uniprovinciales a excepción del murciano, y así el artículo 36, en su redacción original ${ }^{83}$.

Debemos destacar que la opción cántabro-comarcal es una opción de carácter local. La Comarca se plantea no como una parte de la Comunidad Autónoma sino como un ente de carácter local, en este caso no es necesaria sino que es potestativa mediante la ejecución o no de la posibilidad prevista en el Estatuto a través de la Ley concreta reguladora de la materia, posibilidad que no se ha ejercitado hasta el año 1999 y que esta pendiente todavía de ejecución administrativa concreta.

LÓPEZ-MEDEL ${ }^{84}$ señala el encuadre sistemático de dicho artículo dentro del Título tercero bajo la rúbrica «De la Administración», lo cual a su juicio puede revelar una cierta concepción de las entidades comarcales como meros entes descentralizados cuando pueden ser configurados de otro modo como posteriormente él se encarga de afirmar.

En ese sentido debemos recordar que la propia Constitución de 1978 tuvo en el anteproyecto ${ }^{85}$ tuvo en su origen una ubicación sistemática para la Administración Local en el antiguo Título tercero «De la Administración» diferenciándose luego al Título Octavo «De la Organización Territorial del Estado».

82 Jesús LÓPEZ-MEDEL BASCONES, Comentarios al Estatuto de Autonomía de Cantabria, Diputación Regional de Cantabria, 1992, pág. 378 .

83 «En los términos previstos en el artículo 23 de este Estatuto por Ley de Cantabria se podrá:

Uno. Reconocer la Comarca como Entidad Local con personalidad jurídica y demarcación propia. La Comarca no supondrá, necesariamente, la supresión de los Municipios que la integran.

Dos. Crear, asimismo, Agrupaciones basadas en hechos urbanísticos y otros de carácter funcional con fines específicos.».

84 Jesús LÓPEZ MEDEL BASCONES, Comentarios al Estatuto de Autonomía de Cantabria, 1992, pág. 375.

85 Al respecto véase la obra de Sebastián MARTíN RETORTILLO, Comentarios al anteproyecto de Constitución de 1978 sobre Administración Local, Instituto de Estudios de la Administración Local, 1978. 
La determinada definición estatutaria da a juicio de MARTíN REBOLLO ${ }^{86}$ así en primer lugar puede diseñarse la Comarca como un mero soporte de actividades o intervenciones públicas en el ámbito de la agricultura, la educación, de la sanidad, etc., que no supondría ninguna institucionalización ni su consideración como ente local con personalidad jurídica propia. No parece, a nuestro juicio, con la dicción literal del artículo 36 de la Carta institucional fundamental de dicha Comunidad Autónoma.

En segundo lugar afirma Martín Rebollo que la Comarca puede abordarse como demarcación territorial de la propia Comunidad Autónoma como ámbito territorial de su Administración periférica para prestar servicios y ejercer competencias de las Comunidades Autónomas, pero no supone consideración de la Comarca como Ente local, sino como mero ejecutor de las funciones administrativas de la Diputación regional. Y finalmente para el reiterado autor la Comarca como entidad local, como un ente con personalidad jurídica, con una organización y unas competencias propias así como medios técnicos y financieros para el cumplimiento de sus fines, afirmando el citado autor que tiene a su vez una doble vertiente: por un lado puede configurarse como un sustituto de muchos municipios, un ente con competencias e intereses propios a partir de una reforma local que prescinda de los municipios que no puedan prestar los servicios mínimos o bien superar una entidad local para suplir la insuficiencia de los pequeños municipios sin que estos desaparezcan como entes territoriales.

Debemos de tener en cuenta el marco de la garantía institucional municipal determinada por el artículo 150 de la Carta Magna y el procedimiento de creación de Comarcas al que determina el artículo 42 de la Ley Básica de Régimen Local el cual sólo hace viable la Comarca, pese a dicha interpretación, y la interpretación estatutaria de que necesariamente no supo hondar lo cual posibilita un aspecto positivo de supresión de municipios la supresión de las citadas entidades siendo por tanto la Comarca un ente de cooperación o un ente local de segundo grado configurado por la agrupación de municipios.

Por otra parte el artículo 37 del Estatuto ${ }^{87}$ establece una posibilidad delegadora en las Comarcas de funciones propias de la Diputación Regional, lo que coincide con la opinión anteriormente descrita de Martín Rebollo de establecer a la Comarca como posibilidad descentralizada.

Dicha posibilidad articulada por primera vez en este Estatuto ha sido seguida por otros Estatutos como el de la Comunidad Valenciana, el de Castilla y León y el de la Comunidad de Madrid, e igualmente la Ley 7/1985, de 2 de abril, Reguladora de las Bases de Régimen Local en su artículo 27 señala el ejercicio de competencias delegadas. Esas competencias delegadas, reacuérdese, no pueden ser propias de las entidades comarcales sino que se regirán en régimen de delegación y por tanto sometidas a un posible control. Eso sí debe ser fijado por una norma legal aprobada por la propia Asamblea Regional.

Con este mecanismo se posibilita ya una segunda descentralización en Cantabria desde el mismo año 1981, momento de la configuración de la propia Comunidad Autónoma.

\section{II.5. La Rioja}

Por su parte el Estatuto de Autonomía de La Rioja aprobado por Ley Orgánica 3/1982, de 9 de junio, reconoce en su redacción original del artículo $5 .{ }^{\circ}$ que «La Comunidad Autónoma de La Rioja estructurara su organización territorial en municipios y comarcas», siendo modificado dicha redacción originaria en la reforma estatutaria de 1998 y suprimiéndose esa necesidad en cuanto a organización territorial.

Por tanto la experiencia comarcal riojana ha sufrido una variación desde un ímpetu incorporador de la Comarca como entidad supramunicipal de carácter territorial necesaria en toda la Comunidad Autónoma para la propia determinación de la estructura de la entidad autonómica a una mera posibilidad prevista en el artículo 26 del Estatuto ya establecido en la redacción originaria que remitía a ley la regulación de las Comarcas, su creación y competencias, eso sí en el marco de la legislación básica del Estado en materia de régimen local siendo el ejemplo asturiano y cántabro utilizando el título competencial original del 148.1.2. ${ }^{a}$ y hoy en día el título competencial genérico sobre régimen local en el marco de dicha reforma estatutaria de 1999 que supone la variación dejando tan sólo como la propia organización de la Comunidad Autónoma a los municipios por una variación pero que a juicio de FANLO LORAS ${ }^{88}$ dicha reforma no supone que no se puedan constituir las Comarcas puesto que en párrafo

86 Luis MARTÍN REBOLLO, Comentarios al Estatuto de Autonomía de Cantabria, Instituto de Estudios de la Administración Local, 1981.

87 La Diputación Regional de Cantabria ejercerá sus funciones administrativas a través de los organismos y entidades que se establezcan, dependientes del Consejo de Gobierno, y pudiendo delegar dichas funciones en las Comarcas, Municipios y demás Entidades Locales reconocidas en este Estatuto, si así lo autoriza una ley de la Asamblea Regional que fijará las oportunas formas de control y coordinación.

88 Antonio FANLO LORAS, "Problemas de la estructura territorial local de La Rioja”, págs. 9 a 17 de Los espacios de solidaridad territorial como presupuestos del Pacto Local, Gobierno de La Rioja, 2003, y en concreto pág. 9. 
segundo de la vigente redacción del artículo $5 .^{\circ}$ así como en el artículo 27 del Estatuto se reconoce la posibilidad de que el Parlamento de La Rioja pueda crear, reconocer la Comarca como Entidad local con personalidad jurídica propia como una demarcación territorial propia.

Fanlo apunta el posible lapsus del legislador al añadir la frase «que no supondrá necesariamente la supresión de los municipios que la integran» puesto que una interpretación a contrario significa literalmente que puede haber casos en que la Comarca suponga la supresión de los municipios que la integran. Interpretación, que a juicio del citado autor que como ya hemos dicho anteriormente compartimos, supondría la supresión de los municipios y por lo tanto dudas de constitucionalidad.

\section{II.6. Región de Murcia}

Después de La Rioja la siguiente Comunidad Autónoma que accedió a la Autonomía por la vía del artículo 143 fue la de la Región de Murcia, nueva Comunidad Autónoma uniprovincial que suponía el desgaje histórico en su Región de la provincia de Albacete que se incorporó a la Comunidad Autónoma de Castilla-La Mancha, quedando como Región uniprovincial la de Murcia, esto se produjo mediante la Ley Orgánica 4/1982, de 9 de junio.

Murcia ha sido en teoría, en base a sus textos positivos, la Comunidad Autónoma uniprovincial que mayor profundidad ha tenido en el aspecto comarcal. Decimos que al menos en teoría, puesto que en la praxis administrativa y en el desarrollo legislativo no han sido suficientemente cómplices de dichas posibilidades que a nivel estatutario, incluso de legislación sobre régimen jurídico de las Administraciones murcianas se han producido.

De hecho tal y como apunta REINA FERNÁNDEZ ${ }^{89}$ desde el propio Real Decreto-Ley de acceso a la preautonomía ${ }^{90}$ señalaban a la Comarca como un posible elemento estructurante de la Comunidad, de hecho el artículo 3.1 del Estatuto de Autonomía lo consagra ${ }^{91}$.

A diferencia de la redacción originaria de La Rioja o la vigente de Asturias que establece imperativamente una estructura comarcal, en Murcia pese a considerarse un elemento esencial de la organización territorial de la propia Comunidad Autónoma se establece una posibilidad de regulación mediante Ley tanto desde la configuración de los espacios que no quedan determinados por darse diversos criterios los históricos, los naturales, los geográficos, socio-económicos, culturales o demográficos y su propia creación mediante ley autonómica.

En Murcia tal y como afirma Ferreira se establece una doble opción para el legislador autonómico, la articulación interior territorial de la Comunidad Autónoma en torno a Comarcas y la creación de Entidades locales de ámbito comarcal caracterizados lógicamente por la agrupación de municipios limítrofes y por tanto de una Entidad local prototípica de segundo grado.

Así los artículos décimo en cuanto a potestad de autoorganización de la Comunidad Autónoma posibilitarían esa organización territorial interna de la Comunidad, undécimo del Estatuto establecerían una posibilidad de creación de las Comarcas dentro de los límites de la legislación básica del Estado conforme a la ya reiterada posibilidad de creación de Entidades supramunicipales, y finalmente el artículo decimoctavo del Estatuto que establece la característica de la Comarca como entidad territorial y la posibilidad de que por la Comunidad Autónoma se la cedan o deleguen a dicha entidad competencias propias de la Comunidad Autónoma, lo cual implica ese carácter dual nuevamente de parte integrante de la Comunidad Autónoma en su propia organización y de identidad y por tanto sujeto de relaciones interadministrativas por parte de la Comunidad hacia esa entidad que será lógicamente local.

\section{II.7. Comunidad foral de Navarra}

Navarra actualizo por su parte su régimen de autogobierno de carácter foral al régimen constitucional de 1978 en virtud de lo dispuesto en la Disposición Adicional Primera de la Ley de leyes, mediante la Ley Orgánica 13/1982, de 10 de agosto, de Reintegración y Amejoramiento del Régimen Foral de dicha Comunidad.

89 Op. cit., El régimen jurídico de la Comarca, pág. 75.

90 Real Decreto-Ley 30/1978, de 27 de septiembre, por el que se aprobó el régimen preautonómico de la Región de Murcia que señalaba en su exposición de motivos: «Los parlamentarios de Murcia han solicitado al Gobierno un régimen provisional de autonomía con anterioridad a la Constitución. También coinciden en la aspiración común de lograr un futuro régimen autonómico que articule en su día de forma equilibrada todas y cada una de las Comarcas y garantice la descentralización de servicios y funciones, haciendo resaltar la significación de Cartagena... en justa solidaridad y equilibrio... con las demás Comarcas que configuran la Región.».

91 «El territorio de la Región es el de la actual provincia de Murcia, que se organiza en municipios y comarcas o agrupaciones de municipios limítrofes, basadas en criterios históricos, naturales, geográficos, socioeconómicos, culturales o demográficos.

Estas entidades gozarán de la personalidad jurídica y autonomía que les sean atribuidas por las Leyes.» 
En dicho texto debemos destacar que pese a la histórica existencia de las Merindades como circunscripciones supramunicipales que pudieran equiparse al ámbito comarcal el texto del Reintegramiento y Amejoramiento del Régimen Foral no hace ninguna mención expresa al de las Comarcas, aunque sí el artículo $4 .^{\circ}$ de la citada $\mathrm{LO}^{92}$. A juicio de FERREIRA ${ }^{93}$ las Merindades no pueden ser consideradas como un precedente de la institución comarcal aunque no debemos olvidar el carácter esencialmente supramunicipal de un ámbito comarcal o comarcalizante de las referidas Merindades.

El referido texto atribuye a la Comunidad Foral en base al artículo 46.1 todas las competencias históricas que sobre Administración Local le correspondían a la Diputación Foral según la Ley pacionada de 1841, el Real Decreto-Ley pacionado de 4 de noviembre de 1925, así como las que fueran compatibles con estas normas que correspondían a las Comunidades Autónomas o a las provincias en los términos de la legislación básica del Estado.

Evidentemente la no mención de las Comarcas en el texto fundamental del régimen foral no implica la imposibilidad de su creación.

No obstante debemos de señalar la inexistencia tanto del texto de Reintegramiento y Amejoramiento del Fuero como en la Ley de Administración Local navarra del año 1990 de mención expresa a las Comarcas y por tanto de la creación de Entidades Locales supramunicipales de carácter forzoso con personalidad jurídica propia y diferenciada de los municipios.

\section{II.8. Comunidad de Madrid}

El Estatuto de Autonomía de la Comunidad de Madrid aprobado por Ley Orgánica 3/1983, de 25 de febrero, simplemente establece en el artículo 3.3 la misma dicción literal del artículo 152.3 de la Carta Magna ${ }^{94}$. El Estatuto fué modificado mediante Ley Orgánica 10/1994, de 24 de marzo y posteriormente mediante Ley Orgánica en 1998, con amplias referencias a la Administración Pública madrileña. El punto de partida es una vez más la competencia exclusiva que el artículo 26 atribuye a la Comunidad de Madrid en la materia de organización, régimen y funcionamiento de sus instituciones de autogobierno y la unánime declaración de autogobierno del artículo 1 del Estatuto, pero esta vez teniendo presente no sólo las peculiaridades sociales, económicas e históricas, sino también las «administrativas».

De hecho la Ley 2/2003, de 11 de marzo, de administración local, reitera esa posibilidad para las comarcas, pero la dedica un solo artículo, mientras que se ocupa profusamente de las mancomunidades. Debemos acabar destacando en este Estatuto la referencia que en el mismo se contiene en su artículo 5 a la administración periférica al establecer la posibilidad de localizar organismos, servicios y dependencias en otros municipios del territorio de la Comunidad fuera de la villa de Madrid, de acuerdo con criterios de descentralización, desconcentración y coordinación de funciones.

\section{II.9. Illes Balears}

Por su parte en las Islas Baleares y tras la primera Ley Orgánica 2/1983, de 25 de febrero, de Estatuto de Autonomía donde se estableció igualmente un modelo de organización territorial basado en las Islas, las Islas mayores fundamentalmente esto es Mallorca, Menorca e Ibiza con la incorporación de Formentera, que en su artículo 5. ${ }^{\circ}$ establecen las funciones de los Consells insulares que pueden ser capaces de ejercer no sólo las funciones locales a nivel insular de cada entidad supramunicipal tanto en la diputación como las propias de una Comarca sí así existiera, sino también las de la propia Comunidad Autónoma en su término mediante descentralización absoluta que se prevé fuera llevada a sus términos absolutas el propio Estatuto de Autonomía. Tras la reforma y el nuevo Estatuto operado por la Ley Orgánica 1/2007, de 28 de febrero, de reforma del Estatuto de Autonomía de las Illes Balears, en el artículo 8 y bajo la rúbrica de La organización territorial ${ }^{95}$ se regula el tema.

92 «El territorio de la Comunidad Foral de Navarra está integrado por el de los municipios comprendidos en sus Merindades históricas de Pamplona, Estella, Tudela, Sangüesa y Olite, en el momento de promulgarse esta ley.»

93 El régimen jurídico de la Comarca, op. cit., pág. 80.

94 «3. Por ley de la Asamblea de Madrid se podrán establecer, mediante la agrupación de municipios limítrofes, circunscripciones territoriales propias que gozarán de plena personalidad jurídica.»

95 1. La Comunidad Autónoma articula su organización territorial en islas y en municipios. Las instituciones de gobierno de las islas son los Consejos Insulares, y las de los municipios, los Ayuntamientos.

2. Esta organización será regulada, en el marco de la legislación básica del Estado, por ley del Parlamento de las Illes Balears, de acuerdo con este Estatuto y con los principios de eficacia, jerarquía, descentralización, desconcentración, delegación y coordinación entre los organismos administrativos y de autonomía en sus ámbitos respectivos. 
De hecho se produce un cierre del sistema de posible descentralización absoluta, puesto que el nuevo artículo 69. bajo el significativo enunciado de Cláusula de cierre ${ }^{96}$ Por lo que respecta al modelo de administración indirecta y descentralizada, resulta sumamente relevante en nuestro estudio por ser la alternativa a una administración periférica propia, también existente en el caso balear. Así, el Estatuto parte de considerar en su artículo 8 que la Comunidad Autónoma articula su organización territorial en islas y en municipios y que las instituciones de gobierno de las islas son los Consejos Insulares, y las de los municipios, los Ayuntamientos. Y esto ha de ponerse en relación con el artículo 61.3 que establece que «los Consejos Insulares también son instituciones de la Comunidad Autónoma de las Illes Balears». A las que, por otra parte, el artículo 70 les atribuye una lista de veinte competencias propias y el artículo 71 establece otras once posibles sobre las que podrán tener funciones ejecutivas y la posibilidad de obtener más a través del procedimiento de transferencia o delegación que indique una Ley del Parlamento. Para empezar el artículo $80^{97}$ posibilita esa amplia descentralización. Se trata de una opción descentralizadora que se ha llevado a la práctica en no pocas ocasiones. Como es lógico, el artículo 73 les atribuye a los Consejos Insulares la potestad reglamentaria.. Dado el contenido de artículo 80, podemos pensar que lo que se pretendía era dejar claro que, sin perjuicio de que la Comunidad Autónoma de las Islas Baleares pueda ejercer sus funciones a través de otros entes como los Consejos Insulares y los Ayuntamientos ${ }^{98}$, aunque en la caso de la estructura periférica debe de considerarse excepcional, habida cuenta del modelo descentralizado por el que se opta.

Así, la Ley 3/2003 de 26 de marzo, de Régimen Jurídico de la Administración de la Comunidad Autónoma de las Illes Balears es meridianamente clara al determinar en su artículo 4 que «la Administración de la Comunidad Autónoma se estructura fundamentalmente en órganos con competencia central», De este modo, cuando la Ley 3/2003 vuelve a referirse a órganos descentralizados, lo hace en el artículo 5, para referirse a órganos o unidades administrativas que funcionalmente actúen fuera del territorio de la comunidad autónoma. No obstante, de todas las Consejerías existentes, tan sólo encontramos referencias a las Delegación Territorial de Educación en Menorca y a la Delegación Territorial de Educación en Ibiza y Formentera.

\section{COMARCA Y ORGANIZACIÓN TERRITORIAL AUTONÓMICA. EL CASO DE LAS UNIPROVINCIALES}

El modelo de estructuración en Comunidades autónomas previsto por la Constitución de 1978 para España se fundamenta en la agrupación de provincias limítrofes con características comunes que impulsaron el acceso a la autonomía ${ }^{99}$, pero tanto por los avatares del proceso histórico de configuración en Comunidades Autónomas del territorio nacional como por la posibilidad establecida en el propio artículo 143 de la Carta Magna sobre el acceso de «provincias con entidad regional histórica» a la autonomía; lo que, sin perjuicio de la discutible entidad histórica en cuanto a región de alguna de las Comunidades Autónomas constituidas al amparo de dicho precepto abrieron la espita para la generalización de dichas comunidades ${ }^{100}$.

De hecho el informe de la Comisión de expertos sobre autonomías presidida por el profesor García de Enterría desaconsejó la constitución de dichas Comunidades en $1981^{101}$, momento este demasiado tardío para frenar

96 Las competencias no atribuidas expresamente como propias a los Consejos Insulares en este Estatuto de Autonomía corresponden al Gobierno de las Illes Balears, sin que en ningún caso sean susceptibles de transferencia aquellas que por su propia naturaleza tengan un carácter suprainsular, que incidan sobre la ordenación y la planificación de la actividad económica general en el ámbito autonómico o aquellas competencias cuyo ejercicio exija la obligación de velar por el equilibrio o la cohesión territorial entre las diferentes islas.

97 Ejecución de las funciones administrativas. 1. La Administración de la Comunidad Autónoma de las Illes Balears ejercerá sus funciones mediante los entes y los organismos que dependen del Gobierno de las Illes Balears y de los Consejos Insulares y a través de los municipios. 2. El Gobierno de las Illes Balears podrá ejercer la gestión ordinaria de sus competencias a través de los Consejos Insulares y de los Ayuntamientos.

98 Así COLOM PASTOR, Bartolomeu, en "La Administración Pública de la Comunidad Autónoma de las Illes Balears", dentro de La Administración Pública de las Comunidades Autónomas. Coordinador: BASSOLS COMA, Martín. INAP, 2004.

99 Sobre el acceso a la autonomía debemos señalar la posibilidad dispuesta por el artículo 144.b) de la Constitución mediante ley orgánica por motivos de interés nacional de Estatutos de autonomía para territorios que no estén integrados en la organización provincial, previsto para las ciudades autónomas de Ceuta y Melilla (L.O. 1 y 2/1995) y tal y como señala Luis SÁNCHEZ AGESTA «posiblemente» para Gibraltar en El sistema político de la Constitución española de 1978. EDERSA. 1989. Cuestión que mantiene Ángel SÁNCHEZ BLANCO en «La intermunicipalidad». lustel 2004.

100 Una visión general del proceso de configuración de las Comunidades Autónomas la encontramos en "La cuestión regional en España y la constitución del Estado autonómico", págs. 99 a 131 del Curso de derecho público de las Comunidades Autónomas, Montecorvo. INAP 2003, sección 3. ${ }^{a}$, a cargo de Javier Corcuera Atienza.

101 Concretamente en el punto II.2 Correcciones constitucionales a la iniciativas autonómicas señala: «Cree también que no es menos necesario que las Comunidades Autónomas que se constituyan deban ser suficientemente sólidas, con dimensión, población y recursos bastantes para asegurar el óptimo prestacional de los diferentes servicios públicos... ». En efecto, para nuestro Texto fundamental que acceden a la autonomía provincias aisladas es algo rigurosamente excepcional. Tan solo se admite un planteamiento contrario para las provincias que tengan «entidad regional histórica» (artículo 143.1), concepto que no es posible rellenar con meros sentimientos provincialistas ni con abusivas apelaciones a singularidades histórica. Más bien cabe entender que, al margen de casos muy notorios, la Constitución ha establecido una prohibición con reserva de excepción en relación con dichas iniciativas uniprovinciales. En efecto establecidas las citadas excepciones, ninguna provincia puede acceder en solitario a la autonomía si no lo autorizaran previamente las Cortes mediante ley orgánica (artículo 144.1), págs. 16 y 17; y en el punto 
algunos procesos, pero que en la práctica tras el acuerdo que propuso el pacto UCD-PSOE sobre Comunidades Autónomas significó un freno para la constitución de otras Comunidades Autónomas o el inicio de nuevos procesos uniprovinciales, evitando supuesto como el de Segovia ${ }^{102}$ o León, pero no consiguiendo encajar el supuesto de Madrid que fue autorizada a constituirse en Comunidad por la vía del artículo 144.

Por tanto, dad la existencia de la provincia como estructura territorial en nuestro ordenamiento jurídicoconstitucional tal y como se encargó de reseñar nuestro Tribunal Constitucional ${ }^{103}$, la relación de las Comunidades Autónomas con aquellas, ha sido foco de no pocos conflictos entre ambas instituciones supuesto éste que no aparece por razones obvias en las Comunidades Autónomas uniprovinciales que heredan la institución provincial en un nuevo marco político y organizativo que representa la Comunidad Autónoma.

Cabe hacer al menos tres divisiones de Comunidades Autónomas uniprovinciales en este ámbito:

a) En primer lugar la Comunidad Foral de Navarra que en su Ley Orgánica aprobatoria de Reintegración y Amejoramiento del Fuero de 1982 reconoce las competencias de la antigua Diputación Foral de Navarra al Gobierno de Navarra y al Parlamento navarro no estableciendo una entidad local intermedia entre el municipio y la provincia. Subsisten las Merindades pero son circunscripciones y no entidades locales dotadas de autogobierno.

Aquí debemos hacer la misma referencia que se hacia en relación con lo supramunicipal en los territorios históricos vascos puesto que la Comunidad Foral de Navarra tiene su fundamento y naturaleza en la propia Disposición Adicional Primera de la Constitución que reconoce y ampara los derechos históricos de los territorios forales y además en la raigambre y acerbo histórico de una pervivencia de instituciones forales que ni durante el régimen franquista fueron suprimidas en dicho territorio, por lo que la existencia de esas supramunicipalidades está tamizada por esa capacidad de la Comunidad Foral al respecto.

b) Una segunda subdivisión será la referida a la Comunidad Autónoma de las Islas Baleares que tampoco articula un espacio de carácter provincial supramunicipal y local en la propia Comunidad Autónoma, sino que se subsume conforme lo dispuesto en su Estatuto de Autonomía. Ahora bien aquí cabe hacer un símil con al canario en relación con las Islas como entidades locales reconocidas y de carácter territorial existiendo los Consells Insulares como espacio que articulan y representan la supramunicipalidad a nivel del archipiélago balear no tanto sólo en actitudes y materias de carácter local sino tras la profunda descentralización operada en las diversas leyes de Consejos Insulares, incluso de naturaleza plenamente autonómica en la línea de Segunda Descentralización auspiciada desde el año 1999.

c) Finalmente nos encontramos con las Comunidades Autónomas uniprovinciales de régimen común, esto es ni insulares ni forales, y que fundamentalmente han correspondido a Comunidades Autónomas que accedieron a la autonomía a través del procedimiento del artículo 143 de la Constitución Española y que por tanto han asumido rápidamente a partir de los años 1998-1999 competencias sobre desarrollo de las bases del régimen jurídico de las Administraciones Públicas en materia de régimen local y por lo cual sólo a partir de ese momento se han empezado a plantear las posibilidades organizativas derivadas de esa traslación de una supramunicipalidad de naturaleza local, que han sido visto aumentadas dichas inquietudes tras el fenómeno descentralización de la segunda fase de la descentralización política española auspiciada por la Constitución Española de 1978.

IV.2 la iniciativa autonómica que propone el uso de la vía del artículo 144.3 para limitar el acceso «... en su caso de inadmisibles iniciativas autonómicas que puedan resultar abusivas porque, no teniendo amparo directo en la Constitución, se refieren a proyectos de Comunidades Autónomas inviables... " puede consultarse dicho informe de la Comisión de expertos sobre autonomías en el núm. 32 de la Colección Informes - del Centro de Estudios Constitucionales-. Servicio Central de publicaciones de Presidencia del Gobierno. Mayo 1981. Hemos utilizado para el estudio la $3{ }^{\text {a }}$ edición de octubre de dicho año.

102 El caso de Segovia verdaderamente espectacular y muy vinculado a la figura del político Modesto Fraile es descrito por Pedro GONZÁLEZ-TREVIJANO y Cayetano NÚÑEZ RIVERO en El Estado autonómico, principios, organización y competencias, pág. 114. Universitas, S. A., 1998.

103 En general sobre la provincia dentro de la Carta Magna véase Eduardo GARCíA DE ENTERRÍA, "La provincia en la Constitución”, págs. 5 a 17. La provincia en el sistema constitucional. Civitas-Diputación de Barcelona. Obra colectiva dirigida por Sebastián MARTíN RETORTILLO, 1993. En ese sentido debemos recordar que la STC 32/1981, de 28 de julio, sobre la Ley Catalana 6/1980, señala entre otras cuestiones que: «Estos procesos de cambio que la propia Constitución impone o posibilita y que manifiestamente han de conducir a una estructura diferenciada (entre provincias y Comunidad Autónoma, esto es entre Diputaciones y Comunidad) no pueden llevar, sin embargo, a menos que la Constitución sea modificada, a una desaparición de la provincia como entidad dotada de autonomía para la gestión de sus propios intereses. Algunos de los que hoy son tales podrán ser configurados como intereses infraprovinciales y atribuirse su gestión a entidades de esta naturaleza; la defensa y cuidado de otros podrá ser atribuida a la Comunidad Autónoma en la que la provincia se encuentra para ser gestionados por la propia Comunidad. No cabe establecer "a priori" cuál es el límite constitucional de esta reestructuración de las autonomías locales; pero las autonomías garantizadas no pueden ser abolidas, pues la protección que la Constitución les otorga desborda con mucho de la simple "remisión a la Ley ordinaria en orden a la regulación de sus competencias". El legislador puede disminuir o acrecentar las competencias hoy existentes, pero no eliminarlas por entero, y, lo que es más, el debilitamiento de su contenido sólo puede hacerse con razón suficiente y nunca en daño del principio de autonomía, que es uno de los principios estructurales básicos de nuestra Constitución. Esta es manifiestamente la razón de ser del apartado $4 .^{\circ}$ artículo 5 Estatuto de Cataluña.». 
En esa línea se podría plantear un problema sobre si los intereses provinciales exigirían por si mismos una determinada estructura provincial, o en otra formula, tal y como expresa CARRO-FERNÁNDEZ VALMAYOR ${ }^{104}$, o sí garantizan también a primera vista que los intereses provinciales deban de ser de forma necesaria vinculados a un determinado espacio geográfico, dada precisamente su naturaleza de intereses meramente instrumentales a juicio del citado autor en interpretación de las disposiciones del artículo 141.1 de la Constitución en relación con el artículo 36 de la LRBRL, ubicándose en dicha circunstancia dos supuestos distintos: a) La alteración de los límites provinciales que provocase una disminución del número de provincias. b) Por otra parte la conversión, ya citada, de una Comunidad Autónoma pluriprovincial en uniprovincial.

Por lo que respecta al primero de los supuestos de Comunidades pluriprovinciales y alteración de límites provinciales, el citado Carro-Fernández Valmayor mantiene que cumplida la exigencia del artículo 141.1 de la Constitución de reserva de ley estatal no habría ningún impedimento para a través de dicha formula alterar el mapa provincial, no pareciendo un impedimento de carácter absoluto los límites estatutarios de actuales provinciales o los territorios provinciales determinados en el acceso a la autonomía.

Las experiencias y modelos comarcales son muy diferenciados partiendo algunos de una característica esencial para la organización territorial de la propia Comunidad Autónoma, como es el caso catalán, o del principio de vertebración territorial ante la despoblación del conjunto de la Comunidad Autónoma, como es el caso aragonés, o para la mejor prestación de servicios en sentido específico previsto por la circunstancia cántabra que a su vez es Comunidad uniprovincial.

Igualmente podemos hablar de una comarcalización específica o circunscrita a espacios concretos del territorio como fue en su momento la Ley de Alta Montaña catalana de 1983 como la primera norma creadora de Comarcas en el Estado, o supuso el caso del Bierzo en la Ley creadora de dicha Comarca en 1991, única por ahora de Castilla y León.

Entre dichas experiencias cabe resaltar la figura de las Mancomunidades de interés comarcal iniciadas en Aragón y previstas en La Rioja originariamente así como en Castilla y León ${ }^{105}$. Esas Mancomunidades son experiencias previas a la propia comarcalización que intentan realizar esfuerzos en el sentido de concentrar acciones hacía un ámbito comarcal de espacio institucional.

Estos modelos comarcales van igualmente desde la ausencia total de regulación de las experiencias comarcales ni como espacio territorial ni tan siquiera a su mera previsión en las normas estatutarias como ya hemos visto y en las legislaciones de Administración Local de cada una de esas Comunidades Autónomas a su previsión expresa tanto en el ámbito estatutario como en la ley de desarrollo, como es el caso asturiano sin su desarrollo específico y concreto, a la implantación de modelos comarcales totales o parciales diferenciados como el supuesto que vamos a analizar de Aragón, Cataluña en el ámbito de las pluriprovinciales, Cantabria en las uniprovinciales o aspectos singulares como la Comarca del Bierzo en Castilla y León o las Cuadrillas alavesas.

Con carácter general y en relación a la implantación de los sistemas comarcales en las Comunidades Autónomas podemos diferenciar dos períodos evidentes:

a) Por un lado, una primera fase de furibundo comarcalismo, esto es o de ímpetu comarcalizador, lo cual como hemos visto la práctica totalidad de los Estatutos de Autonomía, excepto Navarra y la Comunidad de Madrid, prevén el término Comarca como una posibilidad organizativa tanto en materia de Entidades locales como en bastante de los casos como entidades necesarias para la propia organización territorial de la Comunidad Autónoma.

Este período implica desde la implantación del Estado Autonómico en el año 1978 con las preautonomías coetáneas y así debemos recordar el preámbulo del Real Decreto-Ley de acceso a la preautonomía de la Comunidad Murciana, a la celebración de las segundas elecciones autonómicas en 1987.

En dicho período se gestaron los Estatutos de Autonomía, se procedió a la implantación del sistema comarcal en Cataluña previa la primera fase de los entes comarcales de Alta Montaña de $1983^{106}$, incluso la propia Ley 6/1987 de Ordenación Comarcal de Cataluña, dentro de dicho supuesto ubicaremos la Ley 3/1986, asturiana, de procedimiento de creación de Comarcas.

104 José Luis CARRO-FERNÁNDEZ VALMAYOR, “Autoorganización autonómica y entidades locales”, Revista de Estudios de la Administración Local y Autonómica, número 270, Abril-Junio 1996, págs. 305 a 325, y en concreto 314.

105 Al respecto de dichas Mancomunidades véase Eduardo FERNÁNDEZ GARCíA, "Las Mancomunidades de interés comunitario en Castilla y León”, págs. 83 a 88 de Los espacios de solidaridad territorial como presupuesto del Pacto Local, Gobierno de La Rioja, 2003.

106 Respecto véase “Las competencias de planificación del ente comarcal: La ley catalana de Alta Montaña”, Revista Vasca de Administración Pública, núm. 10, 1985, de Tomás FONT I LLOVET. 
b) Un segundo período señalado entre el referido año 1987 y la celebración de las elecciones autonómicas de 1999, por fijar un hito concreto, es el de enfriamiento y redimensionamiento de la perspectiva comarcal en cuanto organización territorial y aquí podemos señalar la lentitud de implantación competencial y financiera es de las propias Comarcas catalanas, la abstracción de los presupuestos estatutarios comarcales tanto en La Rioja como en Asturias obviándose en un primer caso la Ley de Administración Local de 1990 el término Comarca así como su procedimiento de creación vulnerando a juicio de Ferreira ${ }^{107}$ la redacción del entonces precepto estatutario en cuanto a organización territorial de la Comunidad en Municipios y Comarcas.

Dicho período de enfriamiento podemos destacar la introducción de un régimen comarcal único, geográficamente localizado, una especie de autonomía dentro de la autonomía para el Bierzo en la provincia de León en la Comunidad Autónoma de Castilla y León o la legislación sobre comarcalización sectorial o vinculada a un desarrollo económico y no de carácter territorial, ni de la Comunidad Autónoma, ni en ningún caso de la de régimen local para Galicia.

c) La tercera fase es la de la racionalización del proceso comarcal que implica desde el año 1999 hasta los procesos de reformas estatutarias. En dicho período se promulgan leyes de Administración Local como en el caso de la Riojana o la de Madrid que posibilitan la creación de Comarcas estableciendo los procedimientos o los requisitos necesarios, respetando el régimen básico estatal adoptado por el artículo 42 de la LRBRL, desarrollan procesos comarcales como el aragonés que sí comenzó con la Ley de dicha Comunidad 10/1993 se articula en base a la Ley de Administración Local de 1999 y especialmente la Ley de Medidas de Fomento de Comarcalización del año 2001.

Fruto de dicho período es la Ley de Comarcas de Cantabria de 1999 y en general la elección de la institución comarcal en determinadas Comunidades, sustancialmente Cantabria y Aragón así como parcialmente La Rioja, como posible entidad intermedia de carácter local mientras que en el resto se establecen medidas racionales que posibilitan o bloquean la existencia de Comarcas como soluciones complementarias al ámbito provincial.

d) Una última etapa, por ahora la podemos determinar desde el proceso de aprobación de los Estatutos de segunda generación, que se ha subsumido en la contracción presupuestaria generada por la crisis y con la supresión de entidades locales de segundo grado deficitarias auspiciadas por la LRSAL.

El problema por tanto se plantea en ese doble plano de existencia de organización administrativa en un mismo ámbito territorial, lo cual intento salvar el ya temprano pero postconstitucional informe Enterría sobre las autonomías, en el que debemos incidir con HEREDERO RUIZ DE LA TABLA ${ }^{108}$. La mera lectura de algunos párrafos del informe ${ }^{109}$ es por sí mismo, suficientemente revelador de la contradicción que hemos puesto de manifiesto.

Pero tanto el ámbito de una correcta distribución territorial de los servicios administrativos, como el hueco de entidad local dejado por la supresión de las diputaciones permanece aun irrealizado y por tanto vacante en el

107 Javier FERREIRA, El régimen jurídico de la Comarca, op. cit., pág. 211.

108 Luis HEREDERO RUIZ DE LA TABLA, “Análisis de la evolución y régimen jurídico de la administración periférica de las comunidades autónomas. Especial atención a la Junta de Castilla y León”, 2009, USAL. http://gredos.usal.es/jspui/bitstream/10366/76258/1/DDAFP_HerederoOrtizdelaTablaL_EvolucionyrRegimenJuridicodelaAdministracion.pdf.

109 Dicho informe fue editado por el Centro de estudios constitucionales en 1981 y así: Severas y decididas deben ser las previsiones tendentes a evitar la burocratización de las Comunidades autónomas. La formación de un aparato administrativo extenso debe evitarse tanto en los niveles centrales como en los periféricos. La mayor parte de las provincias que van a quedar integradas en las nuevas Comunidades autónomas soportarían mal que a la antigua centralización estatal sucediera una nueva centralización regional. Y éste es, justamente, el efecto que produciría la asunción de las facultades resolutorias en la mayor parte de los asuntos públicos por los servicios administrativos centrales de cada Comunidad autónoma. Lo mismo puede decirse si la participación provincial se reduce, como ocurre en relación con la Administración estatal, a ofrecer su territorio como sede para los servicios periféricos de la Administración autónoma... Los servicios centrales de las Comunidades autónomas que en adelante se constituyan deben quedar provistos de las dependencias estrictamente precisas para la asistencia a los órganos políticos, para ejercer las funciones de planificación y coordinación que sea necesario desarrollar desde el nivel regional y para atender, en este caso con carácter estrictamente excepcional, aquellos servicios que inevitablemente deban gestionarse desde un nivel territorial más amplio que el provincial. Por lo que respecta a la Administración periférica de la Comunidad autónoma, su creación misma no debe llegar a producirse en ningún caso. Medidas de este orden son las únicas que pueden evitar eficazmente la constitución de los escalones administrativos a sumar a los preexistentes que debilitados (el estatal: artículos 141 y 154 de la Constitución) o fortalecidos (las Corporaciones locales: artículo 137 de la Constitución) han de perdurar. Un esquema organizativo como el propuesto impone lógicamente la utilización necesaria de las Corporaciones locales, y destacadamente de las Diputaciones provinciales para que ejerzan ordinariamente las competencias administrativas que pertenecen a las Comunidades autónomas. Las Diputaciones deben quedar convertidas en el escalón administrativo intrarregional básico: es preciso fortalecer sus servicios, dotarlas mejor, integrar en su organización los servicios periféricos de que se ha de 42 desprender la Administración del Estado, para que puedan asumir el ejercicio de competencias por transferencia o delegación de las Comunidades autónomas y atender ordinariamente la prestación de los servicios que están encomendados a la gestión regional. (...) es ésta una solución general que debe incorporarse a cada Estatuto de autonomía en la fase de su elaboración y aprobación. En la plasmación definitiva de la opción que se propugna están implicadas claramente las potestades de autoorganización de cada territorio y ésta es una cuestión que la Constitución pone a disposición de los Estatutos y sus normas de desarrollo (artículos 147, c y 148.1.1), y en la que para lograr la efectividad de sus propuestas (...), la comisión las remite al pacto que ha de establecerse entre las fuerzas políticas. No obstante lo anterior, el legislador estatal ha de propiciar la solución general referida, aunque no llegue a imponerla, instrumentando jurídicamente la participación de la diputación en la acción administrativa regional. 
espacio de las Comunidades Autónomas de carácter uniprovincial, que a pesar de la recomendaciones de la comisión de expertos sobre autonomías proliferaron; así Asturias, Cantabria, La Rioja, Murcia y Madrid. Dentro de estas comunidades uniprovinciales nos encontramos la especificidad de la Comunidad foral de Navarra con su división territorial en merindades.

Así por ejemplo el artículo 37 del Estatuto de Cantabria ${ }^{110}$ para el caso de las Comunidades Autónomas uniprovinciales de forma analógica, posibilita la delegación de funciones en otras entidades infraautonómicas de competencias de las Comunidades Autónomas.

Incluso las Comunidades Autónomas que han optado por la creación de una generalizada red de entidades supramunicipales de ámbito infraprovincial como Aragón o Cataluña en el caso de las supraprovinciales y Cantabria, aunque embrionariamente, en el caso de las uniprovinciales. Cabe plantearse aquí si la propia Comunidad Autónoma como institución, tal y como señalan los cada uno de los diversos Estatutos de Autonomía al asumir las funciones de las extintas Diputaciones Provinciales, garantiza ese papel supramunicipal de carácter local de asistencia a los municipios y de función de entidad local supramunicipal.

La duda al menos se puede plantear, pero las fuertes centralizaciones administrativas de dichas Comunidades Autónomas estableciendo aparatos administrativos importantes en las capitales, mucho más en los casos de Cantabria, La Rioja y Madrid por el fuerte peso de las capitales sobre la totalidad de la Comunidad Autónoma, menor en Murcia y Asturias por la existencia de diversos núcleos importantes pero también con importantes matices de abandono en cuanto a la descentralización administrativa o desconcentración de la Comunidad Autónoma hacia los municipios más periféricos, puede suponer la existencia de una cierta sensación de falta de atención en el ámbito local de los municipios en sus aspectos supramunicipales.

Prueba de dicha sensación es la existencia de Mancomunidades y otras formas de cooperación intermunicipal que han ido generalizándose en todas estas Comunidades Autónomas, incluso auspiciándose desde aquellas fomentándose o subvencionándose o incluso como en el caso riojano previniendo la existencia de Mancomunidades de interés regional.

De hecho debemos señalar que la falta de legitimidad histórica de las diversas Comunidades Autónomas uniprovinciales incluso tal y como ha señalado BERMEJO LATRE ${ }^{111}$ con cierto carácter algo artificial para los casos de Cantabria, La Rioja, Murcia o Madrid ha hecho que en los procesos de autoafirmación de dichas Comunidades Autónomas sus funciones no hayan sido tan solo de carácter autonómico en lo supramunicipal de la Autonomía sino en todo el ámbito supramunicipal para hacer indispensable la existencia de la Comunidad Autónoma.

Es el espacio jurídico-administrativo es evidente la existencia de un espacio intermedio entre el municipio y la región debemos señalar que dicho concepto de lo supramunicipal ha variado desde que en su momento, por ejemplo MORELL OCAÑA lo abordará112 puesto que la estructura territorial española ha sufrido un giro copernicano tras la Constitución Española de 1978.

No obstante tal y como destaca FERRET JACAS ${ }^{113}$ la Constitución permite la creación de Entes locales distintos del Municipio y la Provincia y sino reserva exclusivamente esta potestad a las Comunidades Autónomas parece conferirles el principal protagonismo en la materia, ahora bien, dichos entes, afirma Ferret, vendrán definidos por un lado por su carácter supramunicipal: constituirán agrupaciones de municipios, por otro lado deberán coexistir con las Provincias.

Pese a la trascendencia y generalización de la institución comarcal en las postrimerías del franquismo y la reivindicación del nacionalismo catalán para su implantación, la Constitución española de 1978 de manera consciente no contempla de forma expresa la palabra «Comarca» o Comarcal, pese a las enmiendas presentadas en este sentido ${ }^{114}$.

110 Por otra parte Cantabria recoge expresamente en su Estatuto la consideración de entidad local de la comarca, aunque deja ésta a una mera posibilidad organizativa desarrollada ya por la Ley de Comarcas 8/1999 pero no ejecutada en su posibilidad práctica de la creación de comarcas concretas.

111 BERMEJO LATRE, José Luis, “El proceso de comarcalización en el Aragón del siglo XxI”, pág. 2, comunicación realizada al Congreso Municipia, Siglo XXI, en Zaragoza. www.dpz/municipio.es.

112 MORELL OCAÑA, Luis, “La nueva Ley de Régimen Local II. La Supramunicipalidad”, Revista Española de Derecho Administrativo, núm. 9/1976, Estudios, pág. 243. Civitas.

113 Joaquín FERRET JACAS, “Entes locales supramunicipales”, pág. 336 de Comunidades Autónomas y Gobiernos Locales, obra colectiva editada por la Diputación de Barcelona en 1987 dentro de la Biblioteca Prat de la Riba con el número 6, en concreto con su aportación sobre Entes locales supramunicipales, págs. 335 a 342.

114 Así el diputado Gastón Sanz presento una enmienda al actual artículo 141.3 con la voluntad de que apareciera de forma expresa el término Comarcas tal y como se puede contemplar en el Diario de Sesiones del Congreso de los Diputados, núm. 88 de 14 de junio de 1978 , págs. 3244 y siguientes. 
Ahora bien a juicio de este autor ${ }^{115}$ la conversión de una Comunidad Autónoma pluriprovincial en uniprovincial tiene más problemática constitucional que la anteriormente señalada alteración de los límites provinciales pues las condiciones para la creación de Comunidades Autónomas uniprovinciales contenidas en los artículos 143.1 y 144.a) de la Constitución Española (recuérdese provincias con entidad regional histórica, territorios insulares uniprovinciales o autorización de las Cortes Generales mediante Ley orgánica cuando no se reúnan los requisitos anteriores, el supuesto de la Comunidad de Madrid), se refieren al proceso constituyente de las Comunidades Autónomas ya cumplido y no a la absorción por las actuales de los entes provinciales sólo una interpretación, a juicio de CarroFernández Valmayor, muy forzada de las normas constitucionales permitiría llegar a tal conclusión, cuestión ésta que también ha reflejado MUÑOZ MACHADO ${ }^{116}$.

En efecto, el citado artículo señala: «Las comunidades autónomas uniprovinciales y la foral de Navarra asumen las competencias, medios y recursos que corresponden en el régimen ordinario a las Diputaciones provinciales. Se exceptúa la comunidad autónoma de las Islas Baleares en los términos de su Estatuto propio».

De hecho ese precepto tiene su origen en la Comisión de expertos sobre Autonomías y en el artículo 15 de la que posteriormente fue la Ley del Proceso Autonómico 12/1983 de 14 de octubre. En ese sentido cabe señalar dos cuestiones apuntadas por la doctrina ${ }^{117}$ : En primer lugar que los órganos que se encargan de defender los intereses de dichas provincias, son los órganos de gobierno propios de la Comunidad Autónoma, sin que hayan creado órganos específicos autonómicos para llevar a cabo esta misión. Y en segundo lugar que la asimilación por parte de las Comunidades Autónomas de las funciones de las Diputaciones Provinciales sólo es posible en las Comunidades Autónomas uniprovinciales y no cabe extrapolar dicho régimen jurídico a las pluriprovinciales.

Es en los referidos argumentos donde encontramos el fundamento cardinal de la existencia de comarcas en las uniprovinciales, dado que la imposibilidad de suprimir la provincia como entidad local y por tanto la necesidad de convivir ésta con cualquier otra entidad local de las previstas en el apartado 2 del artículo $3 .^{\circ}$ de la LRBRL que crearon las Comunidades Autónomas y fundamentalmente las comarcas, como ocurre actualmente en los casos de Aragón y Cataluña, así como singularmente en la provincia de León, lo cual en caso de optarse por una división generalizada en comarcas supone una crisis por oposición de las comarcas con diputaciones, una reduplicación de los niveles y innecesaria conflictividad derivada incluso en muchas ocasiones de los servicios y gastos públicos.

Mientras que por otra parte queda reflejado que las diversas Comunidades Autónomas no han establecido en su seno órganos tan siquiera específicos para la representación y asistencia local en virtud de las funciones del artículo 36 de la LRBRL de cooperación y asistencia y fomento eminentemente locales siendo sustituidas por una vis atractiva del gobierno autonómico correspondiente por funciones directamente prestadas por la Comunidad Autónoma o incluso por funciones de coordinación sobre entidades locales muy directas, cuestión esta que también se produce en las Comunidades pluriprovinciales, pero que esta supeditada al respecto de dicha garantía institucional, circunstancia ésta que en las Comunidades uniprovinciales por obvio al inexistir el referido nivel intermedio de agrupación de municipios con carácter local es imposible que se produzca.

En este caso podemos destacar la existencia de un vacío en el mundo local de agrupación de municipios en defensa de sus intereses específicos de carácter local no vinculados a un interés de carácter autonómico que a veces puede ser contraproducente y opuesto.

De hecho, como hemos visto, las redacciones originarias de buena parte de los Estatutos de Autonomías de las Comunidades uniprovinciales proveyeron la existencia necesaria de un nivel intermedio entre el municipio y la propia Comunidad Autónoma y así fue el caso de Asturias, la Región de Murcia y La Rioja.

Mientras que el Estatuto de la Comunidad de Madrid, que ni siquiera menciona el término comarca, y la actual redacción del Estatuto de La Rioja simplemente prevén la comarca como mera posibilidad de organización sin entrar a calificar la naturaleza de las agrupaciones de municipios o entes comarcales que fueran eventualmente asqueados en uno u otro caso.

Por tanto podemos distinguir en las Comunidades uniprovinciales en relación con la comarca como segundo nivel de la Administración local dos posibilidades:

115 José Luis CARRO-FERNÁNDEZ VALMAYOR, Autoorganización..., op. cit., pág. 315.

116 Santiago MUÑOZ MACHADO, Derecho público de las Comunidades Autónomas, tomo II, pág. 214.

117 En concreto José Vicente MOROTES ARRIÓN en Comentarios a la Ley Básica de Régimen Local, Ley 7/1985, de 2 de abril, Reguladora

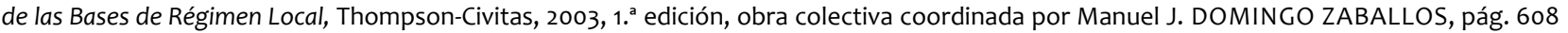
y siguientes. 
Su configuración sea potestativa o sea necesaria. Actualmente los casos de Asturias y la Región de Murcia ${ }^{118}$ pero que nunca ha llegado a desarrollarse más allá de la mera previsión en leyes autonómicas no ejecutadas en su desarrollo que son por una parte la condición de dichos espacios caracterizados por la agrupación de municipios como entidad local y su mera concreción como espacio para la desconcentración o descentralización de la Comunidad Autónoma en cuestión de su propia organización territorial.

Así la Comunidad de Madrid y La Rioja en sus Estatutos simplemente prevén las comarcas como meras posibilidades de organización, sin proceder a calificar la naturaleza de los entes comarcales que sean eventualmente creados ${ }^{119}$.

Pero por otra parte el artículo 141.3 de la propia Constitución señala la posibilidad de crear agrupaciones de municipios diferentes de la provincia, tal y como señala FERRET I JACAS ${ }^{120}$ que al igual que la provincia o podrán tener un doble carácter, el de entidad local y circunscripciones territoriales para desconcentración de los entes territoriales que las englobe.

La base de dicha actuación y fenómeno sería, tal y como señala MUÑOZ MACHADO ${ }^{121}$, el suprimir estrictamente distancias municipales y colocar las administraciones locales en un espacio más comprensivo, más amplio, por tanto echar sobre ellas más responsabilidades, dotarlas de mayores medios, montar administraciones públicas que sean potencialmente mucho más eficientes., que puedan utilizar aquellas administraciones comarcales como órganos eficientes de la administración pública superior. Lógicamente la opción de supresión apuntada por MUÑOZ MACHADO debe ser tenida en cuenta simplemente como un apunte teórico, puesto que debemos recordar el artículo 42 de la LRBRL supone la consagración de la necesidad de existencia institucional del propio municipio, no pudiendo ser la comarca más que una mera agrupación de estos y no suponer la supresión de municipios., por lo que nos encontraríamos ante una estructura federativa de municipios a juicio del citado autor ${ }^{122}$. $Y$ en ese sentido se reabunda la posible introducción de la comarca como nivel de segunda administración local tras la municipal en el esquema de dos niveles en todas y cada una de las Comunidades Autónomas uniprovinciales, por lo que queda claro la posibilidad de un espacio y función para las comarcas en sustitución de las mancomunidades existentes, cuestión diferente sería la sustitución del carácter especializado y voluntario de las mancomunidades por el carácter generalista o limitado a sus ámbitos competenciales genéricos y no prestacionales concretos de las comarcas en relación con las mancomunidades.

De hecho como acabamos de señalar en relación con las mancomunidades existe un auténtico espacio de carácter netamente local y nada autonómico en las Comunidades Autónomas uniprovinciales de carácter intermunicipal o supramunicipal dejando al margen la figura generalizada de las mancomunidades nos encontramos con los propios consorcios y con las áreas metropolitanas y agrupaciones forzosas, aunque aquellas condicionadas por la necesidad de ley autonómica, tal y como se encarga de señalar QUINTANA LÓPEZ ${ }^{123}$.

\section{CONCLUSIONES}

En un panorama de discusión territorial con un sistema de estabilidad presupuestaria y con la necesidad de producir un fuerte ajuste y consolidación fiscal (en especial en las CC.AA) para cumplir con las obligaciones del pacto de estabilidad y crecimiento en la Unión europea, parece un tanto paradigmático y hasta estrambótico el cuestionar la organización territorial de las AA.PP, si no es para reducir estas.

En ese sentido debemos destacar que salvo reforma constitucional poco probable y mucho menos con el grado de consenso alcanzado por el vigente Texto constitucional, una reforma territorial que acabe con el papel de las provincias y por tanto de las Diputaciones por el art. $141 \mathrm{CE}$, no parece muy adecuado.

En cualquier caso y tal como ha reseñado TC en su sentencia 16872016, de 6 de octubre, FJ 3, ante la previsión de la disposición adicional sexta de la Ley 27/2013, puede interpretarse que las previsiones de la reforma local

118 Asturias, Murcia y La Rioja en su redacción originaria, corregida tras la reforma estatutaria de 1998, señalan a la comarca como ente necesario, quedando en la actualidad como una mera posibilidad en el caso de La Rioja, pero dichas redacciones originarias no califican la naturaleza jurídica como entidad local, no obstante las legislaciones de régimen local de las tres Comunidades Autónomas, y así específicamente la Ley 3/86 de 15 de mayo de Asturias de procedimiento de Comarcas, la Ley de Régimen Local y la Ley de descentralización de las entidades locales de Murcia y la Ley de Administración Local de La Rioja prevén a la comarca como entidad local.

119 Así lo señala Joan PRATS I CATALÁ en “La comarca”, op. cit., pág. 836.

120 Joaquín FERRET I JACAS, “Las organizaciones supramunicipales en España. Las Comarcas”, Revista Española de Administración Local y Autonómica, número 254, abril-junio de 1992, pág. 320.

121 Santiago MUÑOZ MACHADO, “Las comarcas y las provincias", págs. 41 a 54 de La comarca como ente territorial, Generalitat de Cataluña, 1984, y en concreto pág. 47.

122 Santiago MUÑOZ MACHADO, “Comarcas y provincias”, op. cit., pág. 48.

123 Tomás QUINTANA LÓPEZ, “Las organizaciones supramunicipales en España: las mancomunidades”, págs. 305 a 317 de Revista Española de Administración Local, número 254, abril-junio de 1992, en concreto pág. 308. 
de 2013 «se aplicarán respetando» toda «organización comarcal» estatutariamente prevista, sin por ello negar o perjudicar la que, no prevista en los Estatutos, pueda eventualmente llegar a instaurar cualquier Comunidad Autónoma al amparo de su competencia en orden a la creación y regulación de entidades locales de segundo grado. Téngase en cuenta a este respecto que la previsión controvertida está formulada en positivo, como cláusula de salvaguarda de las organizaciones comarcales estatutariamente previstas. No cabe interpretarla en negativo, como fuerte restricción a la autonomía de las Comunidades Autónomas traducida en la imposibilidad de ejercer sus amplias competencias en orden a la regulación y creación de entidades caracterizadas por «un fuerte grado de interiorización autonómica».

En cualquier caso y pese a las críticas que las Diputaciones han planteado (sin ir mas lejos en el seminario que propició esta publicación) la articulación de los servicios.

Nos encontramos pues con que la comarca tiene su función y naturaleza como entidad diferenciada, no así como espacio administrativo reiteramos, en el sistema de doble nivel local, el «two tier system» o administración en doble nivel en el cual los servicios locales se distribuyen entre dos entidades. En el primero y más bajo nivel constituido por las entidades territoriales básicas y tradicionales, los municipios fundamentalmente se organizan los servicios más elementales y de menos complejidad organizativa; y en el segundo constituido por entidades especializadas de unidad territorial supramunicipal sin que haya unos servicios más complejos de mayores exigencias organizativas e inversoras.

Tal y como señalaba SÁNCHEZ BLANCO ${ }^{124}$ una posición de favorable a aquellos que pretendan la institucionalización del espacio comarcal, esto es su personificación jurídica fundamentalmente como Entidad local nucleados en torno a la opinión de Martín Mateo ya desde su obra clásica de $1964^{125}$, apoyado por Luis Morell, Florentino Agustín Diez González, José Luis Meilán Gil y Antonio Risco Salanova.

Por otra parte nos encontraremos la visión comarcal de un espacio para la actuación administrativa de entidades superiores en vía de desconcentración, fundamentalmente hoy el espacio de actuación de las Administraciones periféricas de las Comunidades Autónomas.

En cualquier paso y dado nuestro actual marco constitucional y de estabilidad presupuestaria, en la no cerrada crisis, esas posibilidades deben realizarse en elusión de nuevos gastos o en paralelo a la reducción de otros, por lo que en las CC.AA se debería producir un fenómeno descentralizador/desconcentrador, especialmente importante en las CC.AA uniprovinciales.

124 Ángel SÁNCHEZ BLANCO, “La comarca como factor de coherencia regional”, Revista de Estudios de la Vida Local, núm..., págs. 197 a 232, y en concreto pág. 225.

125 Ramón MARTÍN MATEO, La comarcalización de los pequeños municipios, Ministerio de la Gobernación, 1964, págs. 72-73. 